\title{
Microplastic Consumption and Its Effect on Respiration Rate and Motility of Calanus helgolandicus From the Marmara Sea
}

\begin{abstract}
Melek Isinibilir' ${ }^{1}$ Leonid Svetlichny', Taras Mykitchak ${ }^{3}$, Ezgi E. Türkeri' ${ }^{1}$, Kamil Mert Eryalçınn, Onur Doğan ${ }^{5}$, Gülşah Can ${ }^{6}$, Esin Yüksel ${ }^{5}$ and Ahmet E. Kideys ${ }^{6 *}$

${ }^{1}$ Department of Marine and Freshwater Resources Management, Faculty of Aquatic Science, Istanbul University, Istanbul, Turkey, ${ }^{2}$ Department of Invertebrate Fauna and Systematics, I. I. Schmalhausen Institute of Zoology, National Academy of Science (NAS) of Ukraine, Kyiv, Ukraine, ${ }^{3}$ Faculty of Biology, Institute of Carpathian Ecology, National Academy of Science (NAS) of Ukraine, Lviv, Ukraine, ${ }^{4}$ Department of Aquaculture and Fish Diseases, Faculty of Aquatic Science, Istanbul University, Istanbul, Turkey, ${ }^{5}$ Institute of Graduate Studies in Sciences, Istanbul University, Istanbul, Turkey, ${ }^{6}$ Institute of Marine Sciences, Middle East Technical University, Mersin, Turkey
\end{abstract}

OPEN ACCESS

Edited by:

Monique Mancuso, National Research Council (CNR), Italy

Reviewed by:

Xavier Cousin, Institut Français de Recherche pour l'Exploitation de la Mer (IFREMER),

France

Ylenia Carotenuto, University of Naples Federico II, Italy

Gioele Capillo,

University of Messina, Italy

*Correspondence:

Ahmet E. Kideys

kideys@gmail.com

Specialty section: This article was submitted to Marine Pollution, a section of the journa

Frontiers in Marine Science

Received: 06 September 2020 Accepted: 08 December 2020

Published: 23 December 2020

Citation:

Isinibilir M, Svetlichny L, Mykitchak T, Türkeri EE, Eryalçın KM, Doğan O, Can G, Yüksel E and Kideys AE (2020) Microplastic Consumption and Its Effect on Respiration Rate and Motility of Calanus helgolandicus From the Marmara Sea.

Front. Mar. Sci. 7:603321. doi: 10.3389/fmars.2020.603321
Consumption rates of polystyrene microplastics (beads of 6, 12, and $26 \mu \mathrm{m}$ diameter) and their effects on energy metabolism and motor activity of the copepod Calanus helgolandicus living in the Marmara Sea were investigated. All sizes of microplastic particles were actively consumed and excreted via fecal pellets, however, copepods displayed a significant preference for beads sized $6 \mu \mathrm{m}$. In a mixture of algae and microplastics beads of $6 \mu \mathrm{m}$, microplastics consumption rates linearly $\left(r^{2}=0.78\right.$, $n=154$ ) increased 800 times from $50.8 \pm 17.3$ to 8,612 $\pm 5,972$ beads ind ${ }^{-1}$ day $^{-1}$ with an increase in bead concentration from 10 to 44,000 beads $\mathrm{ml}^{-1}$. The total and basal metabolic rates as well as time spent swimming for $C$. helgolandicus, decreased 1.7, 1.8 and about 3-fold, respectively after 7-8 days exposure to microplastic treatments, which was similar to the metabolism and activity of starving animals in filtered water. In copepods consuming microplastics, all vital parameters decreased on the first day of exposure, indicating either accelerated starvation, probably due to increased losses of energy and biological matter in the formation of fecal pellets and/or traumatic/toxic effects of the polystyrene beads on the copepods. Our data from laboratory experiments indicate that the presence of large concentrations of microplastics in water, even when mixed with algae, lowered energy metabolism levels of $C$. helgolandicus.

Keywords: microplastics, consumption, respiration, behavior, Calanus, Marmara Sea

\section{INTRODUCTION}

Microplastics are already numerically one of the most abundant items present in the plankton and sediment of the marine environment (do Sul and Costa, 2014). Removal of microplastics from the marine environment poses one of the greatest challenges for the human race with almost no potential solutions as yet. These facts on microplastics coupled with their ubiquity and availability as false food items for the marine food chain call for dedicated studies on their impact to marine biota (Secretariat of the Convention on Biological Diversity, and Scientific and Technical Advisory Panel GEF, 2012). 
Since the size of microplastics (either $1-1,000 \mu \mathrm{m}$ or 20$5,000 \mu \mathrm{m}$ particles of marine litter, Hanke et al., 2013 or Hartmann et al., 2019, respectively) may coincide with the sizes of phytoplankton cells, many zooplankton species are reported to consume them inadvertently (Huntley et al., 1983; Ayukai, 1987; Cole et al., 2013, 2015, 2016; Lee et al., 2013; Wright et al., 2013; Desforges et al., 2015; Ogonowski et al., 2016; Frydkjær et al., 2017; Scherer et al., 2017; Vroom et al., 2017; Gorokhova et al., 2018; Botterell et al., 2019; Coppock et al., 2019). Generally, zooplanktonic organisms display limited selectivity of food particles feeding upon any available particles of appropriate size. Wilson (1973), Paffenhöfer and Van Sant (1985), and Cole et al. (2013) have shown that many copepod species can ingest microplastics within a size range of 7-30 $\mu \mathrm{m}$ (similar to sizes of their algal food). Smaller microplastics (e.g., $3.8 \mu \mathrm{m}$ as shown by Cole et al., 2013) can externally adhere to the posterior swimming legs of the copepod Temora longicornis. Uptake of microplastics by small zooplankton is very critical, since these lower trophic level species play a significant role in transferring such particles along the whole trophic chain in the marine ecosystem. Therefore, even some zooplankton species which are raptorial predators themselves would be vulnerable to microplastic pollution when their smaller sized prey is contaminated.

Cole et al. (2013) demonstrated that for several species of copepods, exposure to $7.3 \mu \mathrm{m}$ polystyrene beads at concentrations of 4,000-25,000 microplastics $\mathrm{ml}^{-1}$ significantly reduced the feeding rates on algae. This shows that microplastics can significantly affect the health of copepods and their suitability as food items for next trophic levels. It has been recorded that exposure of Calanus helgolandicus to microplastic particles sized $20 \mu \mathrm{m}$ even at low concentrations (75 beads $\mathrm{ml}^{-1}$ ) significantly reduced reproductive output, but there were no significant differences in respiration rates (Cole et al., 2015). We should note that Calanus helgolandicus species is not particularly suitable for studying the effects of diet on energy metabolism since it is naturally adapted to long-term starvation due to its ability to accumulate large lipid reserves (Lee et al., 1970). Indeed, in the experiments of Cole et al. (2015), the active metabolic rate for C. helgolandicus specimens after 10-day exposure to a plastic bead diet averaged $0.7 \mu \mathrm{L} \mathrm{O}_{2}$ ind $^{-1}$ day $^{-1}$ with no significant difference in comparison to controls feeding on microalgae. This indicates that further investigations with different experimental designs are needed to better understand the effects of microplastics on Calanus.

The Sea of Marmara, as well as the Black Sea connected to it by the Bosphorus Strait, is inhabited by the same yearround mass species of the genus Calanus (Isinibilir et al., 2009), which for a long time was attributed to Calanus helgolandicus var. ponticus (Jaschnov, 1955). Later, based on difference in prosome to urosome length relationships and on the occurrence of supernumerary pores on the ventral side of urosome segments in individuals from the Black Sea, the Mediterranean Sea and Atlantic Ocean populations, Fleminger and Hulsemann (1987) recognized the Black Sea population as a distinct species-Calanus ponticus. In 1991, a new name, Calanus euxinus was given to this species by Hulsemann (1991). Repeated morphological comparisons of the Black Sea population with the Atlantic and Mediterranean (Yebra et al., 2011) and the Marmara Sea (Isinibilir et al., 2009) populations did not confirm the comparative morphological measurements by Fleminger and Hulsemann (1987). In addition, it should be taken into account that the difference in the number of urosomal supernumerary pores in Black Sea females may be due to the fundamentally lower salinity of this sea. Finally, by a series of molecular studies, it was shown that level of genetic differentiation between Calanus helgolandicus and Calanus euxinus is typical for conspecific calanoid copepod populations (Papadopoulos et al., 2005; Unal et al., 2006; Yebra et al., 2011; Figueroa et al., 2019) within European waters, despite very distinct geographic barriers/conditions prevail for the Black Sea. Therefore, the species of Calanus in the present study is referred to as Calanus helgolandicus, which has been referred to as C. euxinus or C. ponticus in different studies from the Marmara Sea or the Black Sea.

The aim of this work was (1) to test the ability of Marmara Sea Calanus helgolandicus to consume microplastic beads of three different sizes: 6,12 , and $26 \mu \mathrm{m}$, more or less corresponding to the range of phytoplankton cell sizes they consume, and (2) monitoring changes in metabolic and motor activity rates for a microplastics diet with respect to well fed or starving individuals.

\section{MATERIALS AND METHODS}

Zooplankton samples were collected at the beginning of April both in 2018 and 2019 with a closing Nansen net (opening diameter: $50 \mathrm{~cm}$, mesh size: $200 \mu \mathrm{m}$ ) by vertical hauls from the bottom $(150 \mathrm{~m})$ to the surface at a station located $\left(40^{\circ} 51,715 \mathrm{~N}-28^{\circ} 57,901 \mathrm{E}\right)$ in the Marmara Sea (salinity $22 \mathrm{psu}$, temperature $10-15^{\circ} \mathrm{C}$ ) near the Princes' Islands, off Istanbul, in Turkey. Approximately $2 \mathrm{~h}$ after collecting samples, healthy Calanus helgolandicus specimens were sorted individually at the laboratory, from the diluted sub-samples using a wide pipette. Selected copepods were placed in 1 liter volume vessels containing $0.45 \mu \mathrm{m}$ filtered sea water (20 psu salinity, temp. $17^{\circ} \mathrm{C}$ ) for acclimation to the experimental conditions. Polystrene microplastics (Fluoro-Max Red Dry Fluorescent Particles) of 6 $\mu \mathrm{m}$ (Cat No 36-2), $12 \mu \mathrm{m}$ (Cat No 36-3), and $26 \mu \mathrm{m}$ (Cat No 36-5) were purchased from Thermo ScientificTM.

Our research in April 2018 was focused on preliminary identification of the ability of adult Calanus helgolandicus females to consume microplastic beads along with natural phytoplankton. Further experiments aimed to understand possible preferences between microparticle sizes $(6,12$, and $26 \mu \mathrm{m})$, coupled with measurement of consumption rates of microplastic beads fed in a mixture of monoalgal (Rhodomonas salina) cultured cells. In April 2019, our main research focused on the effect of $6 \mu \mathrm{m}$ microplastics consumption on C. helgolandicus in terms of total and basal energy metabolism and motor activity.

\section{Mono-Algal Culture}

The original strain of the cryptomonad algae Rhodomonas salina (5-10 $\mu \mathrm{m}$ size range) was provided by the Culture Collection 
of Algae and Protozoa (CCAP), Scotland, UK. Initial microalgae cultures were inoculated in test tubes $(30 \mathrm{ml})$ containing $\mathrm{f} / 2+\mathrm{Si}$ medium previously sterilized at $121^{\circ} \mathrm{C}$ for $15 \mathrm{~min}$. All subcultures were maintained at $23^{\circ} \mathrm{C}$ and salinity of 32 psu under a 12L:12D photoperiod. R. salina culture volume was continuously up-scaled from $30 \mathrm{ml}$ test tubes to $250 \mathrm{ml}$ Erlenmeyer flasks, followed by 1,5 , and $30 \mathrm{~L}$ culture containers in photobioreactors, continuously. Illumination was maintained at $200 \mu \mathrm{mol} / \mathrm{m}^{2} / \mathrm{s}$ at the culture surface. Population growth was determined daily by cell counting using Neubauer chambers under Leica DM100 microscope.

\section{Microplastic Uptake Experiments (for Consumption and Fecal Pellet Assessments)}

To determine the rate of microplastic consumption, selected Calanus helgolandicus individuals (under Nikon SMZ-100 microscope) were placed in $1 \mathrm{~L}$ vessels containing $0.45 \mu \mathrm{m}$ filtered sea water of $\left(20 \mathrm{psu}, 17^{\circ} \mathrm{C}\right)$ for preliminary acclimation to the experimental conditions. The following day, actively swimming copepods were picked and individually placed in $10-20 \mathrm{ml}$ cells/vessels for further investigation.

Four feeding (FEED) treatments (up to 5 days) were performed in experiments in April 2018 set up as follows:

(A) To assess the selective consumption of beads of different sizes;

(FEED1): Females were incubated for 3 days in seawater with a mixture of natural phytoplankton (dominated by Skeletonema sp.) collected in the upper layer of the Marmara Sea $\left(\sim 5,000\right.$ cells $\left.\mathrm{ml}^{-1}\right)$ and microplastics of diameter 6,12 , and $26 \mu \mathrm{m}$ (total 5,000 beads $\mathrm{ml}^{-1}$ ), one female per $10 \mathrm{ml}$ vial, (16 replicates). The water and mixture of microplastics/phytoplankton were renewed and sediments were removed every second day. At the end of the 3rd day, the fecal pellets deposited were collected with a pipette, their number was counted. The number as well as the volume of microplastics contained in each pellet was also calculated taking into account the size of beads.

(B) To evaluate the efficiency of microplastic consumption by adult females in the presence and absence of algae, four longer duration experiments (5-6 days) were performed (Figure 1):

(FEED2): Incubation of females for 5 days with only $R$. salina $\left(\sim 5,000\right.$ cells $\left.\mathrm{ml}^{-1}\right)$, two individuals per $50 \mathrm{ml}$, (4 replicates);

(FEED3) Incubation of females for 5 days with a mixture of $R$. salina $\left(\sim 5,000\right.$ cells $\left.\mathrm{ml}^{-1}\right)$ and microplastics of $6 \mu \mathrm{m}$ (5,000 beads $\left.\mathrm{ml}^{-1}\right)$, two females per $50 \mathrm{ml}$ (4 replicates); (FEED4) Incubation of females for 5 days with microplastics of $6 \mu \mathrm{m}\left(\sim 5,000\right.$ beads $\left.\mathrm{ml}^{-1}\right)$, two females per $50 \mathrm{ml}$ (4 replicates).

Two feeding (FEED) treatments (up to 6 days) were performed in experiments in April 2019 set up as follows:
(FEED5): Incubation of females for 6 days with a mixture of $R$. salina $\left(\sim 5,000\right.$ cells $\left.\mathrm{ml}^{-1}\right)$ and microplastics of 6 $\mu \mathrm{m}\left(\sim 5,000\right.$ beads $\left.\mathrm{ml}^{-1}\right)$, one individual per $10 \mathrm{ml}(10$ replicates). The counting of the number of pellets, analysis of their contents, and the renewal of the concentration of the mixture of microplastics and algae along with seawater were performed at the end of each experimental day.

(FEED6): To assess relationship between microplastic concentration and the rate of its consumption (after the first "meeting" of copepods with microplastics), incubation of females for $7 \mathrm{~h}$ in water with $R$. salina (5,000 cells $\mathrm{ml}^{-1}$ ) and microplastics of $6 \mu \mathrm{m}$, gradually increasing the microplastic concentration 2-5-fold hourly from 10 to 44,000 beads $\mathrm{ml}^{-1}$ (one female per $10 \mathrm{ml}, 24$ replicates). At the end of each hour, the number of pellets and beads contained in them was counted whilst the seawater and microplastics were replenished.

The concentration of $R$. salina of $\sim 5,000$ cells $\mathrm{ml}^{-1}$ was typical for many experiments on copepods feeding (Meyer et al., 2002; Carotenuto et al., 2012; Helenius et al., 2019).

For short-term exposures of less than a day, the algae and microplastic concentration was monitored every hour in experimental vessels. In multi-day experiments, concentrations were determined at the end of each day. The experimental conditions did not allow us to use an incubation wheel, but vessels were often shaken during the experiment. It is known that adults Calanus could quickly sink (if they do not deliberately strive to the bottom) and, therefore, spend most of their time at the bottom, even in large vessels, enabling active copepods to filter microplastic beads from the bottom, especially in small $10 \mathrm{ml}$ containers (Treatments FEED1, FEED5, FEED6). With frequent water changes and relatively low temperatures, copepods observed to be quite active even in a multi-day experiment (Treatment FEED5). Maintenance of required concentrations of microalgae and microplastics during experiments (considering bead sizes) were achieved by adding solutions of known concentration to the water determined by a standard method using a hemocytometer.

The microplastic consumption rate was calculated in accordance with number of beads in fecal pellets and the number of pellets per unit time: hourly in short-term and daily in longer-term experiments.

The number and size of pellets were counted under a dissection microscope (Zeiss Opton) at magnification of x16, and microplastic content in pellets were determined under a microscope with an increased magnification of x60-150. To simplify microplastic bead counting, pellets placed on a glass slide were crushed by a coverslip (Figure 1).

\section{Determination of Energy Metabolic Rates}

Energy metabolic rates determined by measuring respiration (RESP) of copepods under different experimental set-ups. During all experiments, approximately 20-50 C. helgolandicus females were constantly kept in 1 liter vessels at a salinity 20 psu and temperature $17^{\circ} \mathrm{C}$ under each of 6 treatments (Figure 2) described below: 

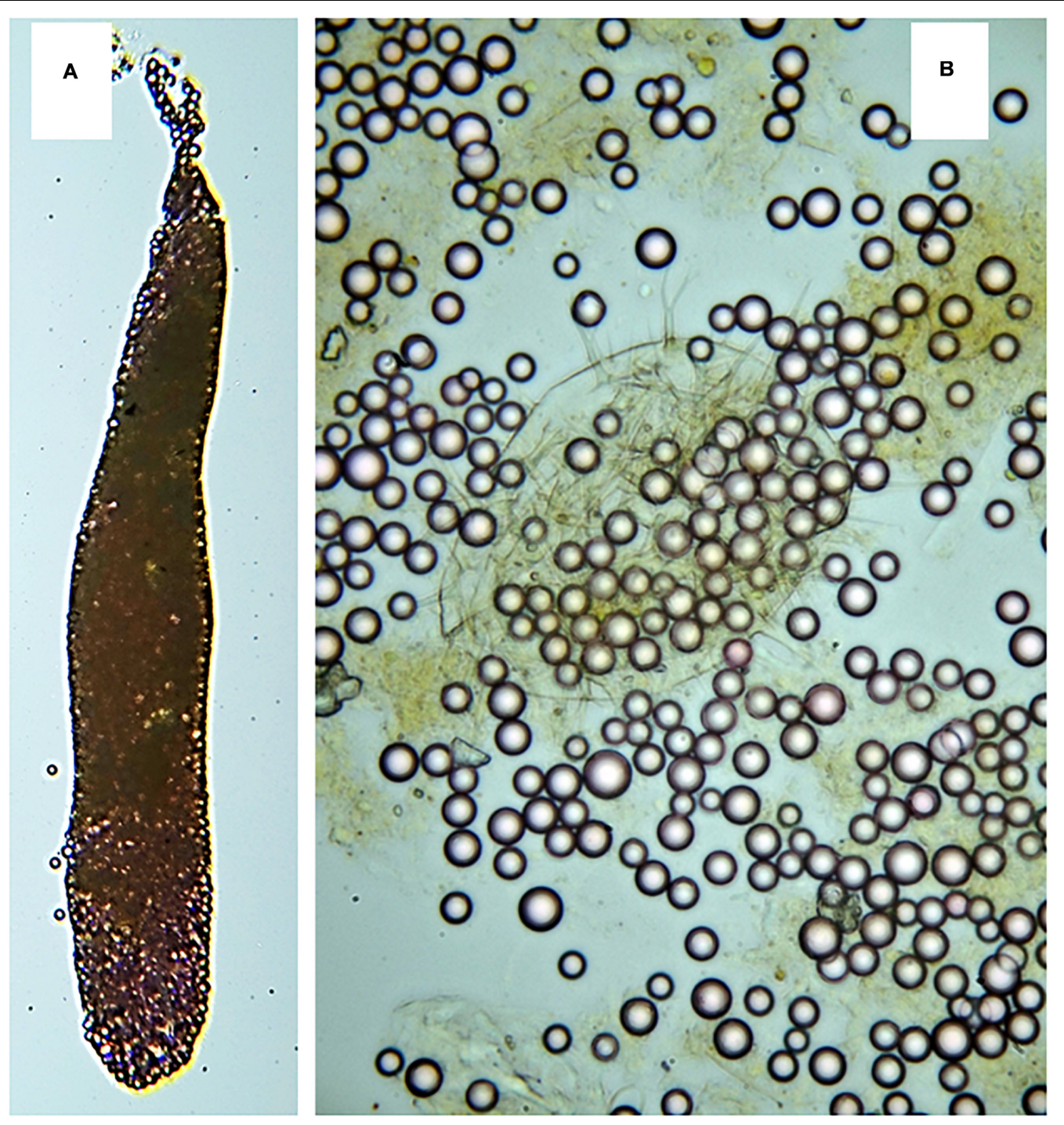

FIGURE 1 | (A) Photograph of an intact fecal pellet-450 $\mu \mathrm{m}$ length and crushed (B) to count plastic beads of sizes 6 and $12 \mu \mathrm{m}$.

(RESP1): Incubation for 3 days with only Rhodomonas salina $\left(5,000\right.$ cells $\left.\mathrm{ml}^{-1}\right)$;

(RESP2): Incubation for 3 days with a mixture of $R$. salina $\left(5,000\right.$ cells $\left.\mathrm{ml}^{-1}\right)$ and microplastics size 6 and $12 \mu \mathrm{m}$ (overall concentration of 5,000 beads $\mathrm{ml}^{-1}$ );

(RESP3): Incubation for 8 days with microplastics size $6 \mu \mathrm{m}$ (5,000 beads $\left.\mathrm{ml}^{-1}\right)$ (6-12 replicates);

(RESP4): Incubation for 7 days in clean filtered water (starvation) (8-15 replicates);

(RESP5): Incubation for 3 days with microplastics size 12 $\mu \mathrm{m}\left(5,000\right.$ beads $\left.\mathrm{ml}^{-1}\right)$ (6 replicates);

(RESP6): Incubation for 3 days with microplastics size 26 $\mu \mathrm{m}\left(5,000\right.$ beads $\left.\mathrm{ml}^{-1}\right)$ (6 replicates).

In addition, a 1 day control experiment after catching specimens was performed ( 9 replicates). Microplastic and/or algal concentrations in water were replenished on a daily basis.
After the start of creating the specified conditions in the treatments, measurements were performed starting from the third day of incubation (except for the first day of starvation). After 3 days, measurements were taken every other day.

Total and basal energy metabolic rates were determined individually from respiration rates of active and anesthetized females at $20^{\circ} \mathrm{C}$ during $1-2 \mathrm{~h}$ of exposition in syringes, slightly higher than the temperature of the containers where copepod stock maintained before experiments $\left(17^{\circ} \mathrm{C}\right.$, which is better for the maintenance of copepods). Thus, our results were comparable with numerous studies of active and anesthetized females of this species, performed by us earlier at a temperature of $20^{\circ} \mathrm{C}$ (Svetlichny and Umanskaya, 1991; Svetlichny and Hubareva, 2005; Svetlichny et al., 2010).

Respiration rates of females were determined individually, using the closed sealed chamber method, by all-glass experimental and control syringes $(2.0 \mathrm{ml}$ volume $)$ used as 


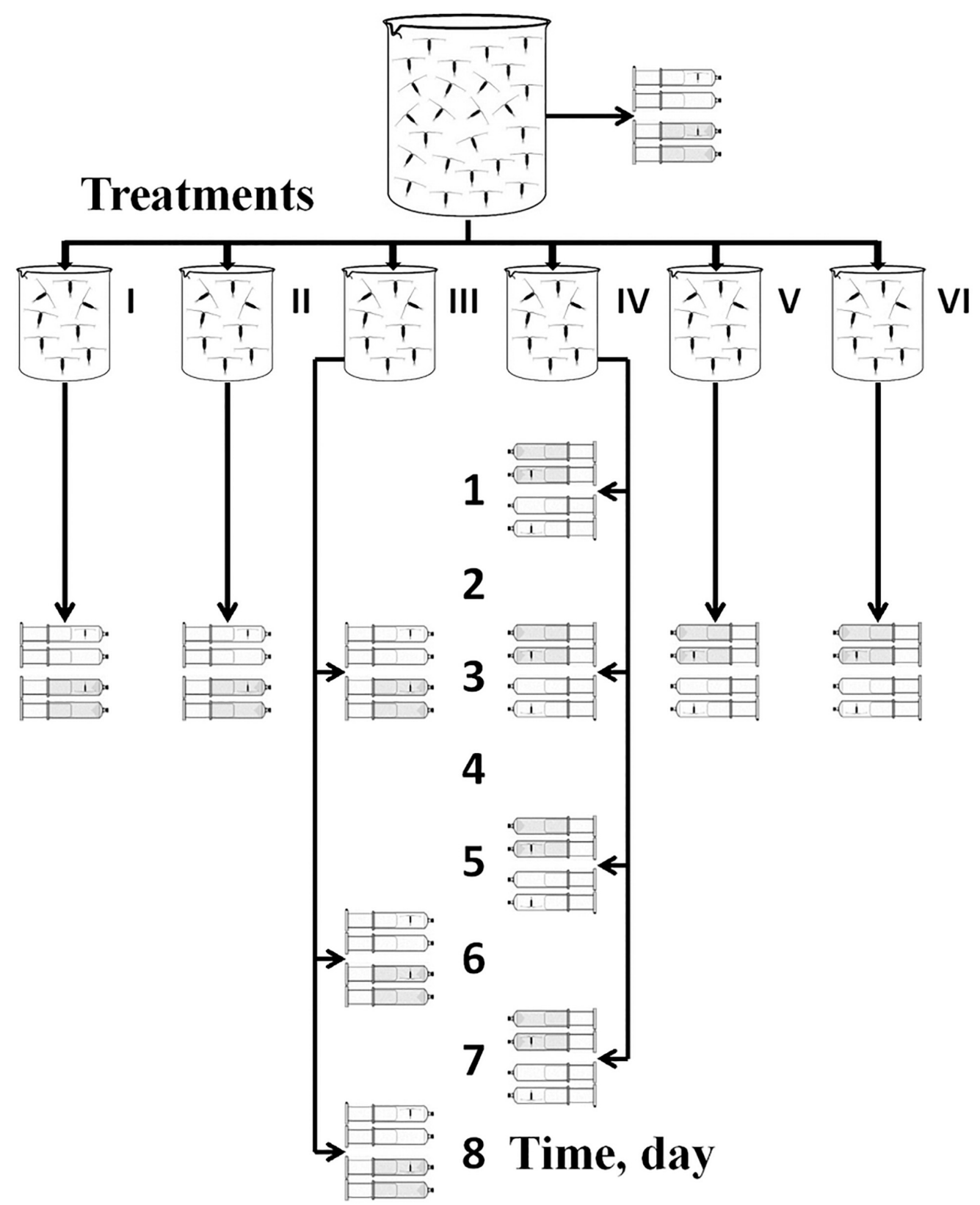

FIGURE 2 | Schematic diagram of the experimental design adopted in the present study for respiration rate experiments. Four syringes for each day of each treatment (I = RESP1, I = RESP2, . . and so on) indicate four types of oxygen concentration measurements: (a) in syringes with active females (gray syringes with copepods), (b) in syringes with anesthetized females (white syringes with copepods) and monitoring oxygen concentration in control syringes for each of the active and anesthetized individuals (syringes without copepods). The number of repetitions for each treatment is given in the text and in Table $\mathbf{3}$.

the respirometers. Females were gently transferred via pipette into an experimental syringe filled with sea water supplied from a protective sieve disc (mesh size $100 \mu \mathrm{m}$ ) at the confluent outlet. In order to obtain identical initial oxygen and seston content, control and experimental syringes were connected to a plastic tube with water gently pumped through and repeated several times. Syringes were then separated, closed with stoppers and placed into the chamber at a constant temperature of $20^{\circ} \mathrm{C}$. Incubation periods were approx. 1 and $2 \mathrm{~h}$ for active and anesthetized females, respectively. Following exposure, water samples from experimental and control syringes were transferred to the small measuring flow chamber of variable volumes (up to $0.3 \mathrm{ml}$ ) and connected to a luminescent dissolved oxygen sensor Hach $\mathrm{LDO}^{\mathrm{TM}}$ in order to measure concentrations of dissolved oxygen.

Oxygen consumption rates of copepods were calculated from differences between final oxygen content in experimental (with copepods) and control syringes (without animals) and expressed 
as the amount of oxygen consumed per individual $\left(\mu \mathrm{gO}_{2}\right.$ ind $\left.^{-1} \mathrm{~h}^{-1}\right)$ or per wet weight $\left(\mu \mathrm{gO}_{2} \mathrm{mg} \mathrm{WW}^{-1} \mathrm{~h}^{-1}\right)$.

Copepods were anesthetized using magnesium chloride (Svetlichny et al., 2010; Svetlichny and Hubareva, 2014) at a concentration of $\left(15 \mathrm{gl}^{-1}\right)$ The same individuals used to calculate total energy metabolic rates were utilized. On average, complete immobilization of $C$. helgolandicus females occurred after $10 \mathrm{~min}$. Immediately after immobilization, copepods were transferred to the experimental syringes containing filtered sea water with a twofold lower concentration of magnesium chloride, enough for copepods to remain immobile during the $2 \mathrm{~h}$ exposure period. During incubation, syringes with anesthetized animals were rotated every $10 \mathrm{~min}$ to avoid the development of $\mathrm{O}_{2}$ gradients within the water volume. After incubation, individuals were gently transferred to fresh seawater where length and width measurements were obtained. Only results of experiments in which the copepods did not mobilize during incubation but only recovered activity post-incubation were analyzed. Individuals subjected to anesthesia were not used in further experiments.

Body wet weight (WW, mg) was calculated as $\mathrm{WW}=\rho \mathrm{V}$ where $\rho$ is body density, taken to be $1.05 \mathrm{mg} \mathrm{mm}^{-3}$ and $\mathrm{V}$ is body volume $\left(\mathrm{mm}^{-3}\right)$ which was calculated according to Svetlichny et al. (2012).

\section{Behavior Monitoring}

Motor activity parameters of copepods (total duration of swimming, frequency of locomotor patterns) were determined by video recording at $60 \mathrm{fps}$ with a Nikon $1 \mathrm{~V} 1$ camera equipped with a long-focus lens (scale $\sim 1: 4$ ) under inactive artificial lighting. 5-10 individuals were placed in transparent glass aquaria $(50 \times 30 \times 70 \mathrm{~mm})$ with filtered sea water, containing microalgae, or microplastics, or a mixture of both. Several 1 min recordings were repeated within an hour under the given experimental conditions.

Frequency and kinematic parameters of mouth appendage movement were determined using high-speed (1,200 fps) filming with a Nikon $1 \mathrm{~V} 1$ camera at higher magnification (scale $\sim 1: 1$ ) for shorter periods of time $(\sim 5 \mathrm{~s})$. Illumination aboard the vessel was provided via a narrow-beam $5 \mathrm{~W}$ led lamp. At least 10 replications for each individual were performed.

The following parameters of locomotor activity were determined in copepods; (a) feeding on microalgae ad libitum before starvation; (b) after 1 day of exposition on microplastics of $6 \mu \mathrm{m}$ alone and starvation in clean water; (c) after 7 days of exposition on microplastics of $6 \mu \mathrm{m}$ alone and starvation in clean water; (d) after the addition of microalgae at the end of the 7 th day of starvation.

\section{Statistical Analyses}

All data were tested for normality with the Shapiro-Wilk test, homogeneity of variances by Levene's test, and treated using one-way ANOVA. Means were compared by the two-tailed Student's $t$-test $(p<0.05)$ and Duncan's Multiple Range Test (DMRT) using SPSS software (SPSS for Windows 11.5; SPSS Inc., Chicago, IL, United States). Duncan's Multiple Range test (DMRT) is a post hoc test to measure differences between pairs of means (which are shown as a, b, c, bc, d, cd, etc. in relevant figures below). In this test, whilst same letters mean no significant difference, different letters indicate significant differences among pairs of means. Linear correlation was used to determine the relationship between proportion of the initial consumption rate and day, microplastic consumption rate and microplastic concentration in the water. Correlation coefficients $\left(R^{2}\right)$ and significance $(P<0.05)$ were then calculated using regression analysis. Values presented in the figures and tables are means \pm standard deviations $S D$. All values presented as percentage were arc cosine transformed before performing any statistical test.

\section{RESULTS}

\section{Microplastics Bead Consumption and Size Selectivity}

In our investigations, almost immediately after the addition of microplastics to the experimental vials containing either natural phytoplankton (dominated by Skeletonema sp.) or Rhodomonas salina culture, adult females began to actively consume the microplastics, as evidenced by the large numbers of beads in the fecal pellets. No mortality of Calanus helgolandicus specimens was noted in all experiments, With the exception of two dead females after 6 days, no other mortalities of Calanus helgolandicus specimens were noted for all experiments.

In a 3 day feeding experiment (treatment FEED1), where C. helgolandicus specimens were exposed to natural phytoplankton and microplastics (diameters 6, 12, and 26 $\mu \mathrm{m})$ in equal concentrations $\left(\sim 5,000\right.$ cells/beads $\left.\mathrm{ml}^{-1}\right)$, the average fecal pellet production rate (FPPR) reached 24 pellets female $^{-1}$ day $^{-1}$. Duncan's Multiple Range test (DMRT) showed that relative shares of microplastics of $6 \mu \mathrm{m}(82.0 \pm 10.1 \%$ of total) were significantly higher ( $t$-test, $\mathrm{df}=45, P<0.05$, $n=16$ ) in fecal pellets (Figure 3) compared to their relative concentrations in the water $(65.4 \pm 8.9 \%$ of total). For the two other size groups (i.e., 12 and $26 \mu \mathrm{m}$ ), relative concentrations of microplastics in fecal pellets $(13.2 \pm 8.7$ and $4.9 \pm 4.5 \%$, respectively) were lower than those in water $(25.3 \pm 6.4$ and $9.5 \pm 3.1 \%$, respectively) indicating preferential feeding on $6 \mu \mathrm{m}$ sized beads by $\mathrm{C}$. helgolandicus.

During 5 day experiments with females fed different diets: Rhodomonas salina only, a mixture of $R$. salina and $6 \mu \mathrm{m}$ microplastics and exclusively $6 \mu \mathrm{m}$ microplastics (treatments FEED2, FEED3, and FEED4), FPPR varied widely from $6.0 \pm 2.0$ pellets female ${ }^{-1}$ day $^{-1}$ at the beginning of treatments FEED2, to $36.7 \pm 17.6$ pellets female ${ }^{-1}$ day $^{-1}$ in treatment FEED3 (Table 1). In general, no significant difference was observed in the average FPPR between treatments for the entire experimental period, with the exception of Day 1, when the FPPR in treatments FEED3 and FEED4 proved significantly higher $(P<0.05)$ than in FEED2. However, during these treatments, the number of microplastic beads decreased 5 and 8-fold in treatments FEED3 and FEED4 respectively, while microplastics consumption rates (MBCR) decreased by 3.7-fold during 4 days of exposure in treatment FEED3 and 11.5-fold during 5 days of exposure in treatment FEED4 (Table 1). 


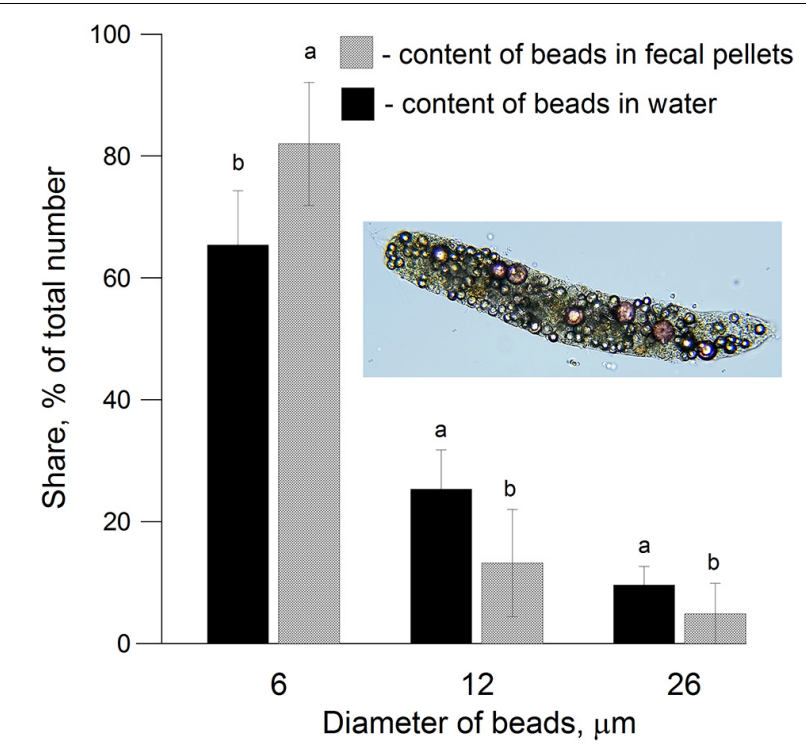

FIGURE 3 | Percentage share of different sized microplastic beads (6, 12, and $26 \mu \mathrm{m}$ ) in water and fecal pellets of Calanus helgolandicus on 3 day of incubation (microplastics and mixed phytoplankton were offered as food in equal concentrations ( 5,000 cells $\left.\mathrm{ml}^{-1}\right)$. Low-case letters $(\mathrm{a}, \mathrm{b})$ are the significant variable differences from Duncan's Multiple Range test (DMRT), $P<0.05$.

Fecal pellet sizes differed depending on copepod diet (Table 2) but displayed no definite relationship to numbers of beads within. Maximum pellets size $(0.58 \pm 0.11$ length, $0.08 \pm 0.01 \mathrm{~mm}$ width) was found for copepods feeding on pure microplastics (Treatment FEED4) which was significantly higher than pellets of individuals fed an algal diet (Treatment FEED2 and FEED3) $(P<0.05)$.

In the experiment designed to assess the effect of microplastics on consumption rates in the long-term, the average microplastics consumption rate by individuals, expressed as a percentage of the initial consumption rate, significantly decreased by approximately 3 -fold $\left(R^{2}=0.9861, P<0.05\right)$ over 6 days (Figure 4) of exposure to a mixture of microplastics $(6 \mu \mathrm{m}$,
TABLE 2 | Fecal pellet sizes for Calanus helgolandicus females obtained after $24 \mathrm{~h}$ from different diet treatments (Mean \pm Standard Deviation $S D$, low-case letters denote significant variable differences between means of different treatments using Duncan's Multiple Range test, $P<0.05$ ).

\begin{tabular}{lll}
\hline Treatments & Length, $\mathbf{m m}$ & Width, $\mathbf{m m}$ \\
\hline FEED2 & $0.41 \pm 0.08^{\mathrm{b}}$ & $0.06 \pm 0.01^{\mathrm{b}}$ \\
FEED3 & $0.45 \pm 0.10^{\mathrm{b}}$ & $0.06 \pm 0.01^{\mathrm{b}}$ \\
FEED4 & $0.58 \pm 0.11^{\mathrm{a}}$ & $0.08 \pm 0.01^{\mathrm{a}}$ \\
\hline
\end{tabular}

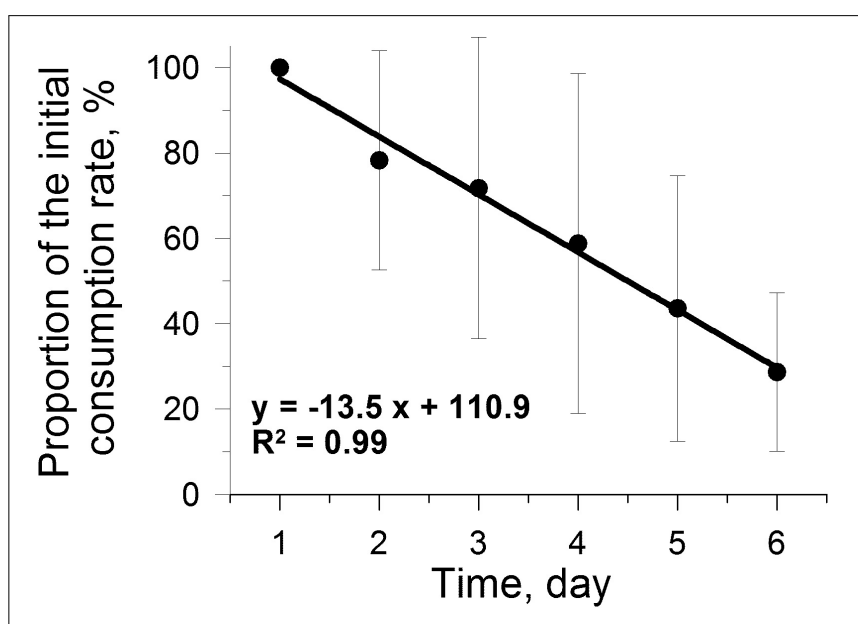

FIGURE 4 | Relative change in consumption rates of Calanus helgolandicus during 6 day experiment feeding on a mixture of microalgae Rhodomonas salina $\left(\sim 5,000\right.$ cell $\left.\mathrm{ml}^{-1}\right)$ and $6 \mu \mathrm{m}$ microplastics $\left(\sim 5,000\right.$ beads $\left.\mathrm{ml}^{-1}\right)$ $(P<0.001)$.

$\sim 5,000$ beads $\mathrm{ml}^{-1}$ ) and Rhodomonas salina algae $\sim 5,000$ cells $\mathrm{ml}^{-1}$ (Treatment FEED5).

During a $7 \mathrm{~h}$ experiment (designed to assess short term relationship between consumption rate and microplastics concentrations) in a medium containing Rhodomonas salina $\left(5,000\right.$ cells $\left.\mathrm{ml}^{-1}\right)$ and $6 \mu \mathrm{m}$ microplastic beads (Treatment FEED6), C. helgolandicus females showed a statistically significant increase $\left(\mathrm{y}=11.2 \times{ }^{0} .66 ; R^{2}=0.78, P<0.001\right.$,

TABLE 1 | Fecal pellet production rates (FPPR, pellets female ${ }^{-1}$ day $^{-1}$ ), microplastic beads numbers in one pellet (BP, beads $\times 10^{3}$ pellet ${ }^{-1}$ ) and daily microplastics beads consumption rates (MBCR, beads $\times 10^{3}$ female $^{-1}$ day ${ }^{-1}$ ) of Calanus helgolandicus females in the 5 day experiments with algae Rhodomonas salina and microplastics of $6 \mu \mathrm{m}$ diameter $\left(5,000\right.$ cells/beads $\mathrm{ml}^{-1}$ ) (values expressed in Mean \pm Standard Deviation SD, low-case letters denote significant variable differences between means using Duncan's Multiple Range test, $P<0.05)$.

Day

Treatments

(FEED2) Algae (FEED3) Algae $R$. salina + microplastic beads

(FEED4) Microplastic beads R. salina

\begin{tabular}{|c|c|c|c|c|c|c|c|}
\hline & $\begin{array}{c}\text { FPPR, pellets } \\
\text { female }^{-1} \text { day }^{-1}\end{array}$ & $\begin{array}{l}\text { FPPR, pellets } \\
\text { female }^{-1} \text { day }^{-1}\end{array}$ & $\begin{array}{l}\text { BP, beads } x \\
10^{3} \text { pellet }^{-1}\end{array}$ & $\begin{array}{l}\text { MBCR, beads } \times 10^{3} \\
\text { female }^{-1} \text { day }^{-1}\end{array}$ & $\begin{array}{c}\text { FPPR, pellets } \\
\text { female }^{-1} \text { day }^{-1}\end{array}$ & $\begin{array}{l}\text { BP, Beads } x \\
10^{3} \text { pellet }^{-1}\end{array}$ & $\begin{array}{c}\text { MBCR, beads } x \\
10^{3} \text { female }^{-1} \text { day }^{-1}\end{array}$ \\
\hline 1 & $6.0 \pm 2.0^{\mathrm{C}}$ & $19.5 \pm 18.9^{b}$ & $1.9 \pm 0.7^{a}$ & $27.9 \pm 14.3^{b}$ & $32.5 \pm 12.8^{a}$ & $1.6 \pm 0.4^{b}$ & $52.1 \pm 13.4^{a}$ \\
\hline 2 & $10.3 \pm 7.2^{b}$ & $9.0 \pm 5.6^{b}$ & $2.0 \pm 0.8$ & $19.0 \pm 7.1^{b}$ & $16.8 \pm 1.7^{a}$ & $1.8 \pm 0.3$ & $30.4 \pm 4.7^{a}$ \\
\hline 3 & $14.8 \pm 8.5^{b}$ & $10.3 \pm 9.2^{\mathrm{c}}$ & $0.2 \pm 0.007$ & $2.8 \pm 0.1^{b}$ & $28.3 \pm 14.1^{\mathrm{a}}$ & $0.2 \pm 0.002$ & $5.1 \pm 0.06^{a}$ \\
\hline 4 & $30.3 \pm 23.9^{a}$ & $36.7 \pm 17.6^{a}$ & $0.2 \pm 0.006$ & $7.4 \pm 0.2^{a}$ & $18.4 \pm 5.3^{c}$ & $0.2 \pm 0.001$ & $3.4 \pm 0.02^{b}$ \\
\hline 5 & $21.5 \pm 9.3^{\mathrm{c}}$ & $31.8 \pm 20.4^{a}$ & $0.4 \pm 0.3$ & $16.5 \pm 11.2^{\mathrm{a}}$ & $24.5 \pm 14.1^{b}$ & $0.2 \pm 0.0005$ & $4.5 \pm 0.01^{b}$ \\
\hline
\end{tabular}




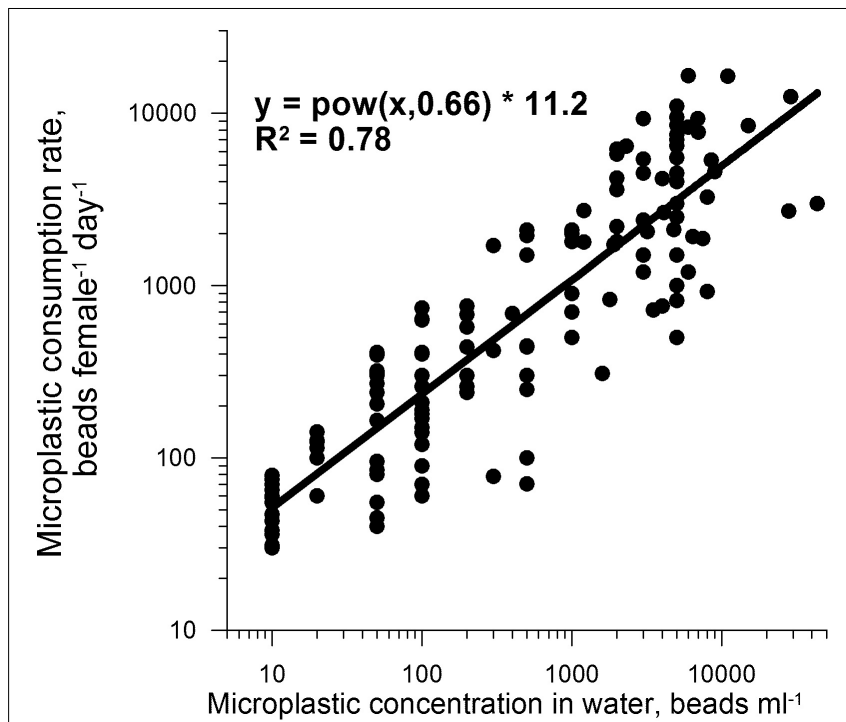

FIGURE 5 | Consumption rates of $6 \mu \mathrm{m}$ diameter microplastics (estimated by numbers of beads in fecal pellets inspected hourly) in $C$. helgolandicus females exposed for $7 \mathrm{~h}$ to water containing Rhodomonas salina ( $\sim 5,000$ cells $\mathrm{ml}^{-1}$ ) and different amounts of microplastic beads (10-44,000 beads $\mathrm{ml}^{-1}$ ).

$n=154)$ in microplastic consumption rates from $50.8 \pm 17.3$ to $8,612 \pm 5,972$ beads female day $^{-1}$ as microplastic bead concentrations increased from 10 to 44,000 beads $\mathrm{ml}^{-1}$ (Figure 5).

\section{Effects of Microplastic Consumption on Energy Metabolism}

Weight-specific respiration rates (WRR) of active and anesthetized females (for total and basal metabolism, respectively) exposed to a mixture of concentrated natural phytoplankton $\left(\sim 5,000\right.$ cells $\left.\mathrm{ml}^{-1}\right)$ immediately after selection in the laboratory were $1.15 \pm 0.09$ and $0.5 \pm 0.11 \mu \mathrm{g} \mathrm{O}_{2}$ $\mathrm{mg}^{-1} \mathrm{~h}^{-1}$, respectively. Corresponding WRR values obtained were very similar for the experimental group fed 3 days with the algae Rhodomonas salina in the same concentration (active females $(1.14 \pm 0.2$ and anesthetized females $0.45 \pm 0.04 \mu \mathrm{g}$ $\mathrm{O}_{2} \mathrm{mg}^{-1} \mathrm{~h}^{-1}$ (Figure 6, Treatment RESP1). Surprisingly, WRR of active females starved during 3 days was only slightly lower $\left(1.08 \pm 0.2 \mu \mathrm{g} \mathrm{O}_{2} \mathrm{mg}^{-1} \mathrm{~h}^{-1}\right.$, Figure 6, Treatment RESP4) than those fed with natural phytoplankton or $R$. salina. Duncan's Multiple Range test (DMRT) showed that there was no significant difference between the WRR values of RESP1 (fed with R. salina) and RESP4 (starved) for the active metabolism.

However, in active females kept for 3 days in a mixture of algae and microplastics (Treatment RESP2), WRR values were 1.4-fold lower than in females consuming the algae diet only (Figure 6). In females that consumed only microplastics of 6 and $12 \mu \mathrm{m}$ (Treatments RIII and RV, respectively), in addition to a decrease in the WRR's of active individuals, the WRR's of anesthetized individuals also significantly $(P<0.05$ using DMRT) decreased by 1.7 -fold. WRR's for both active and anesthetized individuals (for total and basal metabolism, respectively) were especially

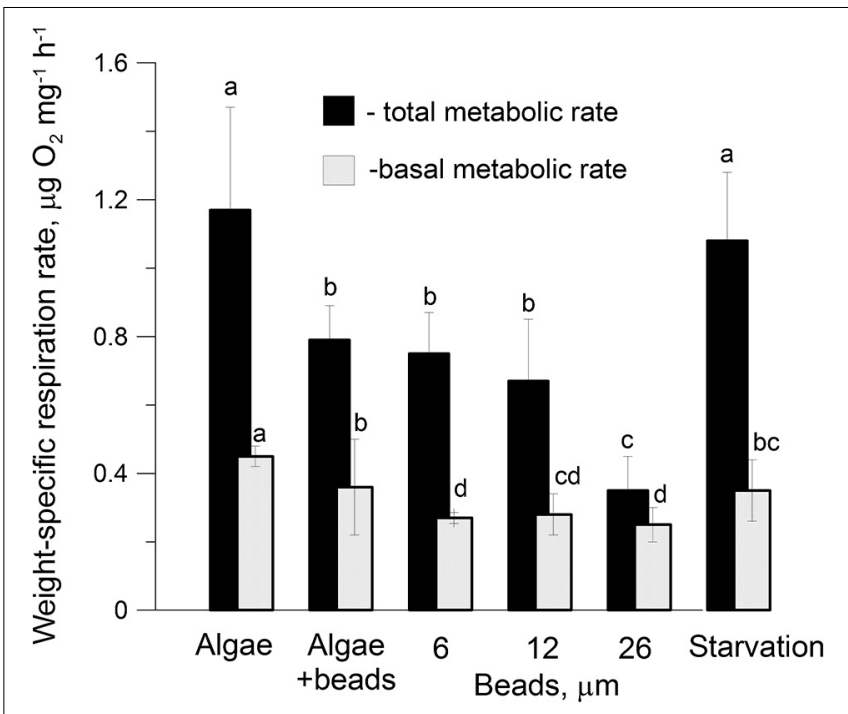

FIGURE 6 | Weight-specific respiration rates of active (black bars) and anesthetized (gray bars) (for total and basal metabolism, respectively) Calanus helgolandicus females on the 3rd day of the experiment (see Figure 2). Specimens were fed algae Rhodomonas salina (Treatment RESP1), a mixture of algae $R$. salina and microplastics of 6 and $12 \mu \mathrm{m}$ diameter $(5,000$ cells/beads per ml, Treatment RESP2), microplastic beads of 6, 12, and 26 $\mu \mathrm{m}$ diameter at concentrations of 5,000 beads/ml each (Treatments RESP3, RESP5, and RESP6, respectively) and starvation (Treatment RESP4). (Low-case letters (a, b, bc, c, cd, d) denote significant variable differences among means of different treatments from Duncan's Multiple Range test, $P<0.05)$.

low in females consuming only microplastics beads of $26 \mu \mathrm{m}$ diameter $\left(0.35 \pm 0.1\right.$ and $0.25 \pm 0.06 \mu \mathrm{g} \mathrm{O} \mathrm{O}_{2}$ ind $^{-1} \mathrm{~h}^{-1}$, respectively) (Figure 6).

In an 8 day experiment with females fed a diet of $6 \mu \mathrm{m}$ microplastics (Treatment RESP3), the WRR of both active $\left(1.21 \pm 0.18 \mu \mathrm{g} \mathrm{O}_{2}\right.$ ind $^{-1} \mathrm{~h}^{-1}$, indicating total metabolism) and anesthetized individuals $\left(0.45 \pm 0.09 \mu \mathrm{g} \mathrm{O}_{2}\right.$ ind $^{-1} \mathrm{~h}^{-1}$, indicating basal metabolism) decreased significantly $(p<0.001)$ by 1.6 -fold to minimum levels by the third day, while the decline of the WRR of starving females was gradual over the course of 7 days (Treatment RESP4) (Figure 7A and Table 3). Metabolic scope of activity (SA, Figure 7B), characterizing energy expenditure of motor activity alone and defined as the difference between the WRR's of active and anesthetized individuals, decreased for both treatments from 0.76 to 0.45 $\mu \mathrm{g} \mathrm{O}_{2}$ ind $^{-1} \mathrm{~h}^{-1}$, accounting for approximately the same share $(\sim 63 \%)$ of total metabolic rates of active females. This amounted to approximately 1.8 -fold of basal metabolic rates for immobilized individuals in both maintenance regimes.

\section{Effect of Microplastic Beads on Locomotory Activity}

Unfortunately, we did not conduct long-term parallel experiments with algae-eating copepods, given our many old observations of copepod behavior and our control experiment on respiration rate of feeding females. For example, we showed 


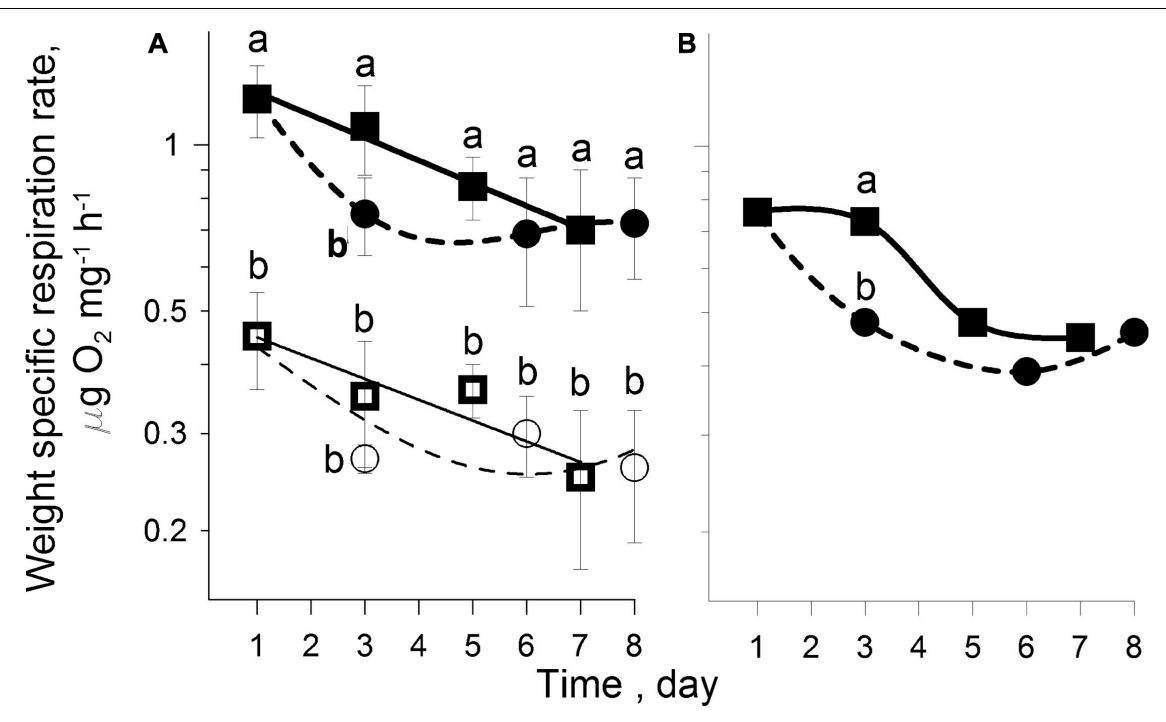

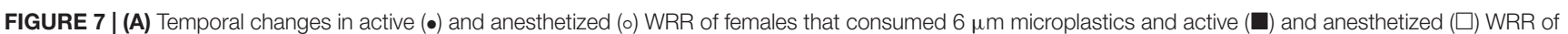

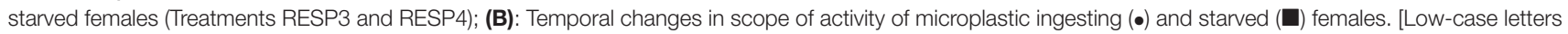
(a,b) denote significant variable differences between each active and anesthetized groups using Duncan's Multiple Range test, $P<0.05]$.

TABLE 3 | Total and basal weight specific respiration rates $\left(\mu \mathrm{g} \mathrm{O}_{2} \mathrm{mg}^{-1} \mathrm{~h}^{-1}\right)$ of active and anesthetized Calanus helgolandicus females respectively, exposed to starvation (except Day 1 of experiment) and microplastics [number of replications in parenthesis, Mean \pm Standard Deviation $S D$; low-case letters $(a, b, c)$ denote significant variable differences among each active and anesthetized groups using Duncan's Multiple Range test, $P<0.05]$.

\begin{tabular}{|c|c|c|c|c|}
\hline \multirow[t]{2}{*}{ Days } & \multicolumn{2}{|c|}{ Starvation } & \multicolumn{2}{|c|}{ Consumption of microplastics } \\
\hline & Active & Anesthetized & Active & Anesthetized \\
\hline 1 & $1.21 \pm 0.18(8)^{\mathrm{a}}$ & $0.45 \pm 0.09(5)^{b}$ & - & - \\
\hline 3 & $1.08 \pm 0.2(15)^{\mathrm{a}}$ & $0.35 \pm 0.09(7)^{\mathrm{c}}$ & $0.75 \pm 0.12(6)^{b}$ & $0.27 \pm 0.016(4)^{\mathrm{c}}$ \\
\hline 5 & $0.84 \pm 0.11(12)^{\mathrm{a}}$ & $0.36 \pm 0.04(6)^{b}$ & - & - \\
\hline 6 & - & - & $0.69 \pm 0.18(12)^{a}$ & $0.3 \pm 0.05(6)^{b}$ \\
\hline 7 & $0.7 \pm 0.2(8)^{\mathrm{a}}$ & $0.25 \pm 0.08(4)^{b}$ & - & - \\
\hline 8 & - & - & $0.72 \pm 0.15(8)^{\mathrm{a}}$ & $0.26 \pm 0.07(8)^{b}$ \\
\hline
\end{tabular}

(Svetlichny and Yarkina, 1989) that in females of C. helgolandicus, the average daily swimming time is about $50-70 \%$, and the frequency of the mouth appendages, equal to $40-50 \mathrm{~Hz}$ at $20^{\circ} \mathrm{C}$, can be maintained in laboratory conditions for tens of days and depends only on the temperature of the water. So, despite lack of control group, we could safely assume that copepods feeding with algae would have similar result after 7 days. This is also confirmed by our new inclusion of data (not included in the Ms before) from measurements after the addition of microalgae at the end of 7th days of starvation (see end of section "Behaviour Monitoring" as well as Figure 8).

Calanus helgolandicus individuals were most active in water containing a natural mixture of planktonic algae or Rhodomonas salina. In some observations they were seen to continuously swim and feed in the water column for several seconds, but on average the time spent swimming was $43.9 \pm 18.1 \%$ of total observation time, the frequency of movement of the mouth appendages was $41.3 \pm 5.2 \mathrm{~Hz}$ (Figure 8). At the end of the first day, the time spent for swimming remained approximately the same for both starved and fed with 6 microplastics of $6 \mu \mathrm{m}$ groups, however, frequency of locomotion significantly decreased to $31.7 \pm 4.3$ and $32.9 \pm 3.3 \mathrm{~Hz}(P<0.05)$ respectively for these groups. On the 7 th day of fasting in clean water and water containing microplastics of $6 \mu \mathrm{m}$, the females were mainly observed at the bottom of the vessel, producing short intervals of mouth appendages movement. Time spent swimming decreased to 11.6 and $16.6 \%$ in starving and microplastic consumed females, respectively, however, the frequency of strokes by mouth limbs significantly decreased to $25.7 \pm 3.5 \mathrm{~Hz}$ only in females consuming microplastic $(P<0.05)$. After the addition of microalgae to the aquarium, in which the behavior of females starving for 7 days was recorded, the frequency of their locomotion remained approximately the same $(37.02 \pm 6.7 \mathrm{~Hz})$, however, the time spent swimming significantly $(P<0.05)$ increased by almost five times up to $54.9 \pm 15.1 \%$.

\section{DISCUSSION}

\section{Microplastic Consumption}

Calanus helgolandicus relates to calanoid copepods that feed on phytoplankton cells due to the water flow generated by their highly bristled mouth appendages (Cannon, 1928). Initially it was assumed that their action is like a primitive filtering device. Boyd (1976) proposed that the second maxillae of C. helgolandicus, generally behave as "leaky sieves," retaining food particles larger than their intersetule distance. Nival and Nival (1976) concluded that individuals of $C$. helgolandicus were capable of consuming particles less than $5 \mu \mathrm{m}$ in size. However, according to a review by Hansen et al. (1994), the optimal algal diet size for adult calanoid 


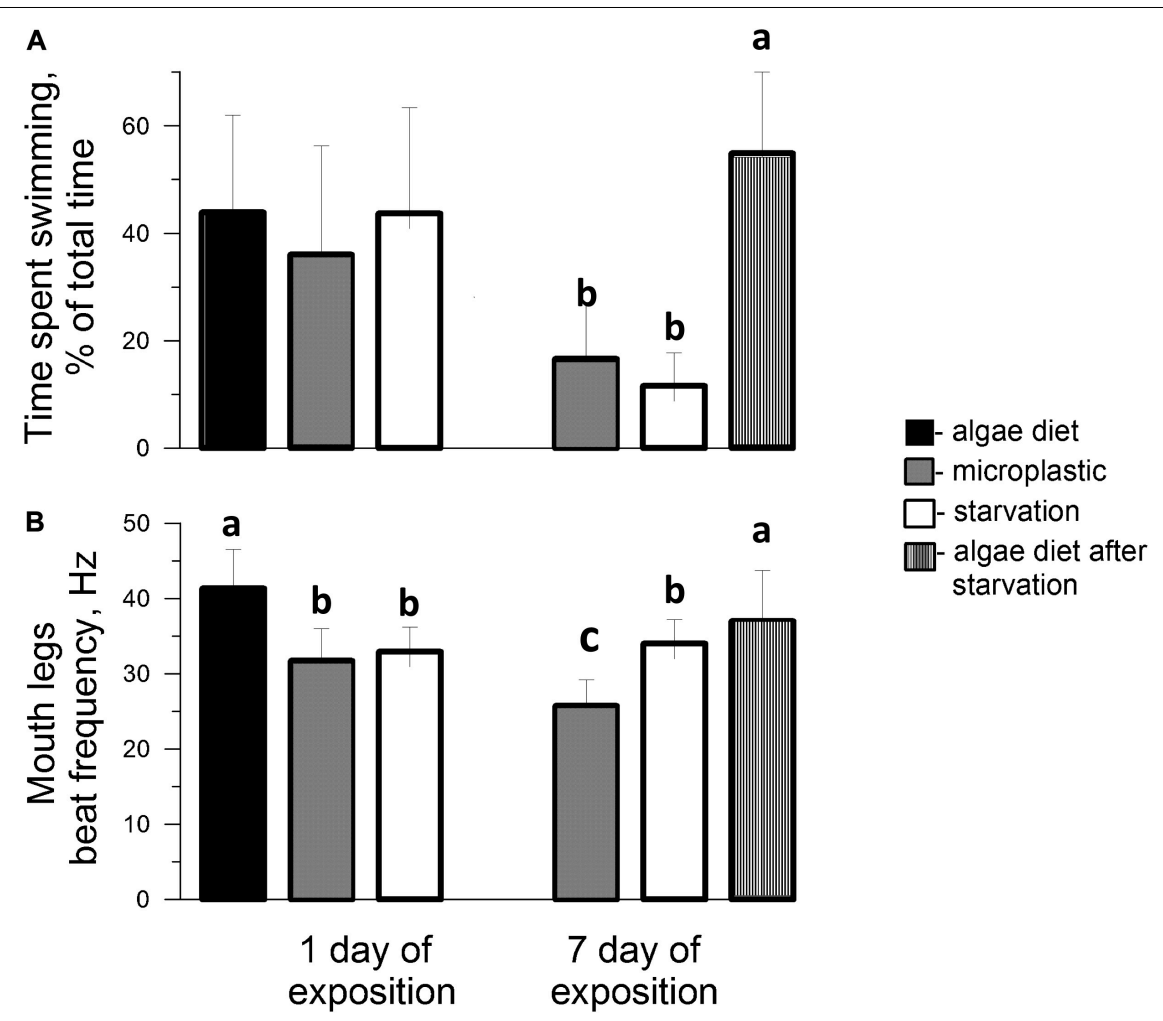

FIGURE 8 | Time spent swimming (A) and mouth appendage beat frequency (B) in adult females feeding on Rhodomonas salina ( $\square$ ), microplastics of $6 \mu$ m size ( $\square$ ) and starved ( $\square$ ) on Days 1 and 7 of experiments (Treatments RESP3 and RESP4) and adding microalgae to the aquarium with females starved 7 days (the most right bars with vertical lines). Low-case letters denote significant differences between means using Duncan's Multiple Range test $(P<0.05)$.

copepods varies between 14 and $80 \mu \mathrm{m}$, while the minimum is $4-9 \mu \mathrm{m}$.

Studies, performed using high-speed movies of feeding calanoid copepods, showed that their modes of particle capture involve complex behaviors, quite unlike those attributed to passive filter-feeders. Calanoid copepods can collect, manipulate and reject individual particles (Koehl and Strickler, 1981; Price et al., 1983; Koehl, 1984; Price and Paffenhofer, 1984; Cowles et al., 1988) and can perceive their motile prey remotely due to chemosensory abilities (Poulet and Marsot, 1978) and via hydromechanical signals using mechanoreception (Kiørboe, 2011; Gonçalves and Kiørboe, 2015).

Although calanoid copepods are able to discriminate between edible and inedible food, their ability to consume non-edible particles of the same size has long been known e.g., organically coated and non-coated polymer spheres (Poulet and Marsot, 1978; Vanderploeg et al., 1990) latex particles (Hansen et al., 1991), suspended silicon carbide powder (Sew et al., 2018), polystyrene spheres (DeMott, 1986, 1988), and various other types of microplastic debris (e.g., Cole et al., 2013, 2015, 2016; Setälä et al., 2014; Coppock et al., 2019). This may be due to the fact that non-food particles entering the water quickly become coated with bacteria (Rummel et al., 2017; Vroom et al., 2017; Rist and Hartmann, 2018) and may mimic the organic detritus they consume, or acquire the "smell" of algae, such as diatoms, which secrete mucus into the water. Specially flavored spheres were actively consumed by copepods in the experiments of DeMott (1986, 1988).

Total amount of microplastic beads in the deposited pellets indicates the end point of all latent processes that can exert their influence on different time scales. Many previous studies have shown a high correlation between the rate of food intake and the rate of fecal pellet formation in copepods (Corner et al., 1972; Gamble, 1978; Paffenhöfer and Knowles, 1979; Ayukai and Nishizawa, 1986; Tsuda and Nemoto, 1990; Paffenhofer et al., 1995). Therefore, defecation rate may be used to derive ingestion rate (e.g., Reeve and Walter, 1977; Båmstedt et al., 1999).

In our experiments adult Calanus helgolandicus consumed microplastics of sizes 6,12 , and $26 \mu \mathrm{m}$ presented to them, regardless of the presence or absence of algae in the water. However, they displayed selective preference for the smallest particles of 6 microns. The proportion of $6 \mu \mathrm{m}$ microplastics in fecal pellets was significantly higher (i.e., 1.25-fold) than in the water, while concentrations of 12 and $26 \mu \mathrm{m}$ microplastics in pellets were almost half of those in water (Figure 3 ).

It is possible that since the small phytoplankton of the diatom complex (Skeletonema costatum) prevailed in the field in April (both in 2018 and 2019), copepods sampled for the experiment may have been already adapted to feeding on small particles. Indeed, the same diatom species (Skeletonema costatum) has been repeatedly used previously in laboratory cultivation of Calanus helgolandicus (e.g., Huskin et al., 2000; Rey et al., 2001). 
Huntley et al. (1983) showed that closely related copepods of Calanus pacificus sp. consume polystyrene beads of similar sizes to diatoms and Peridinium algae. These and our findings are consistent with the conclusion of Cole et al. (2015) that Calanus helgolandicus were not able to differentiate between microplastic beads and algae of a similar size.

In our experiments, when $6 \mu \mathrm{m}$ microplastic beads were added to the water, the females immediately began to consume with the first fecal pellets appearing at the bottom of the vessel after $7 \mathrm{~min}$. This corresponds to the maximum gut passage time for calanoid copepods (Mauchline, 1998).

During a 1 day exposure to a mixture of $6 \mu \mathrm{m}$ microplastics and $R$. salina of similar size (at a constant concentration of 5,000 cells $\mathrm{ml}^{-1}$ ), the consumption of microplastics by $C$. helgolandicus continuously increased from $50.8 \pm 17.3$ to $8,612 \pm 5,972$ beads female $^{-1}$ day $^{-1}$ with the increase in microplastic concentration from 10 to 44,000 beads $\mathrm{ml}^{-1}$ (Figure 5). The very large variability in number of fecal pellets deposited (average value $26.3 \pm 13.4$ pellets female ${ }^{-1}$ day $^{-1}$ ) did not enable determination of dependence of pellet production on the concentration of presented microplastics, however, numbers of beads in pellets significantly increased at a concentration range of $10-5,000$ beads $\mathrm{ml}^{-1}$ from $15.5 \pm 13.1$ to $1449.9 \pm 867.8$ beads pellet ${ }^{-1}$.

Considering that the volume of one $6 \mu \mathrm{m}$ microplastic

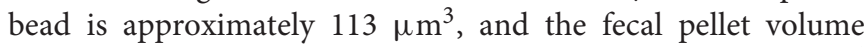
of $C$. helgolandicus females averaged approximately $2.9 \times 10^{6}$ $\mu \mathrm{m}^{3}$, the volume fraction of microplastics in pellets, despite their huge abundance, averaged only $5.6 \%$. This is probably why in our experiments no correlation was found between fecal pellet size and microplastics consumption rate. Close correlations of pellets volume were observed in C. helgolandicus from the western English Channel both at low microplastic concentrations of 75 beads $\mathrm{ml}^{-1}$ (Cole et al., 2016) and high concentrations of approx. 1,000 beads $\mathrm{ml}^{-1}$ (Coppock et al., 2019) up to $1.7 \times 10^{6}$ and $2.2 \times 10^{6} \mu^{3}$, respectively, and was even higher than pellet volumes $\left(1.4 \times 10^{6} \mathrm{\mu m}^{3}\right)$ of $C$. helgolandicus during bloom conditions in the North Sea (Riser et al., 2003), but less than $3.26 \times 10^{6} \mu^{3}$ observed in the closely related Calanus pacificus, which also consumed a natural diet (Uxye and Kaname, 1994). According to a review by Martens (1978), the largest pellets of $C$. helgolandicus can reach $650 \mu \mathrm{m}$ with a volume of about $5 \times 10^{6} \mu \mathrm{m}^{3}$.

In general, both the sizes and the production of pellets in C. helgolandicus in our experiments corresponded to the ranges previously known for this species feeding on a natural diet (Mauchlin, 1998; Huskin et al., 2000).

Summarizing the data obtained, it can be stated that, although at the beginning of $C$. helgolandicus exposure to a mixture of algae and microplastics of the $6 \mu \mathrm{m}$ preferred size, they actively began to consume it in proportion to the concentration in the water, during the next 5 days, the microplastic consumption rates decreased several fold identified as a decrease in the microplastic content of pellets (see Table 3 ). This was probably a consequence of the reaction of copepods to a high mean concentration of microplastics $\left(\sim 5,000\right.$ beads $\left.\mathrm{ml}^{-1}\right)$, since at low concentration $\left(\sim 75\right.$ beads $\left.\mathrm{ml}^{-1}\right)$ a similar effect was not observed (Cole et al., 2015).
The feasibility of studying effects of high concentrations of small (several microns in size) microplastics on marine organisms has been debated recently (e.g., Huvet et al., 2016; Lenz et al., 2016) in light of the understandable methodological difficulties in assessing actual concentrations at sea. Although the levels of larger microplastics $(>100 \mu-5 \mathrm{~mm})$ from the marine environment are measured for many coastal areas, smaller microplastics of $(<26 \mu)$ are not known and could be much higher than that larger microplastics. A wide range of experimental concentrations is therefore extremely important for predicting the consequences of the development of negative scenarios of plastic pollution. Small suspended particles originating both from natural and anthropogenic sources are a common occurrence in the marine (especially coastal) environment. For example, high concentrations of suspended sediments occur within the vicinity of dredging and reclamation works (Erftmeijer et al., 2012). Similarly, high levels of larger sized microplastics in the influent and effluent of wastewater treatment plants have been reported (Hidayaturrahman and Lee, 2019). In any case, it should be emphasized that experiments in laboratory conditions incorporating high microplastic concentrations are useful in order to explore the possible impacts at marine ecosystems levels.

\section{Respiration}

C. helgolandicus belong to the group of cruising feeder calanoids, who spend most of their total daily energy budget on finding and extracting food particles along their routes (Kiørboe, 2011). This part of the energy budget is called metabolic scope of activity (SA) determined by the difference between the total respiratory rate of active and basal respiratory rate of anesthetized individuals (see Hochachka and Somero, 2002). A significant part of the energy supplied by food is also consumed in the digestion process referred to as specific dynamic action of food (SDA) (Kiørboe et al., 1985; Thor, 2002; Svetlichny and Hubareva, 2005). Together with the costs of maintaining the body (basal energy metabolism, $\mathrm{BM}$ ), these components add up the total energy metabolism (TM), estimated by the respiration rate of active individuals. It is known that at maximum speed and duration of movement, the respiration rates of planktonic crustaceans can increase 3-7 times (Pavlova and Minkina, 1987; Svetlichny and Umanskaya, 1991; Buskey, 1998; Svetlichny and Hubareva, 2002). Therefore, their energy metabolism should be more sensitive to the motor activity of crustaceans than to the consumption and digestion of food.

In our experiments, weight specific rates (WRR) of active C. helgolandicus females well fed by a mixture of phytoplankton algae or starved during 1 day insignificantly varied within 1.14-1.21 $\mu \mathrm{g} \mathrm{O}_{2} \mathrm{mg}^{-1} \mathrm{~h}^{-1}$, while the WRR of immobilized, anesthetized individuals was 2.3-2.6 times lower $(0.45-0.5 \mu \mathrm{g}$ $\left.\mathrm{O}_{2} \mathrm{mg}^{-1} \mathrm{~h}^{-1}\right)$. In females starving for 3 days, the corresponding values decreased to $1.08 \pm 0.2$ and $0.35 \pm 0.09 \mu \mathrm{g} \mathrm{O}_{2} \mathrm{mg}^{-1} \mathrm{~h}^{-1}$, respectively, however, the difference between TM and BM, which characterizes expenditure on motor activity, remained almost the same $\left(0.73 \mu \mathrm{g} \mathrm{O}_{2} \mathrm{mg}^{-1} \mathrm{~h}^{-1}\right)$, or $63 \%$ of TM. Assuming that a significant decrease in BM of starved, anesthetized females compared with active copepods is due to the cessation of digestive activity, i.e., SDA, their value should be about $9 \%$ of TM. A close 
share in BM, SDA, and SA values of TM was found in females of this species undertaking almost continuous cruising swimming (Svetlichny and Hubareva, 2005).

In our 3 day respiratory experiment, on $C$. helgolandicus females feeding on a mixture of algae and microplastics or microplastics alone, TM, BM, and SA were even lower than for starved individuals. SA decreased especially significantly in individuals who consumed large microplastics of 26 $\mu \mathrm{m}$ (Figure 7).

With longer exposure of females in a suspension of $6 \mu \mathrm{m}$ microplastics beads and starvation conditions (8 and 7 days, respectively), the levels of TM, BM, and SA decreased by $\sim 1.8$ fold compared to the initial levels to the same extent, however, the decrease in energy metabolism of individuals on a plastic diet in the initial days of the experiment was faster (Figure 8). One of the reasons for this, requiring further research of clarification, may be the additional expenditure of energy and loss of biological material by females consuming microplastics on the formation of a peritrophic membrane covering fecal pellets (Gauld, 1957), which consists of chitinous microfibrils and a ground substance containing acid mucopolysaccharides and proteins (Yoshikoshi and Ko, 1988). Indeed, FPPR in starved females (Treatment RESP4, not marked in results) did not exceed 2 pellets female ${ }^{-1}$ day $^{-1}$, while in females consuming microplastics it reached $32.5 \pm 12.8$ pellets female ${ }^{-1}$ day $^{-1}$ (Table 1 ). The decrease in energy metabolism during starvation in C. helgolandicus, like other species of this genus (Conover, 1962; Ikeda, 1971, 1977; Mayzaud, 1976), is a consequence of physiological adaptation to the experience of prolonged starvation due to the large number of reserve lipids (Lee et al., 1972).

In general, our data indicates that the presence of large concentrations of microplastics in water, even when mixed with algae, reduces the level of total energy metabolism due to a decrease in both basal and active metabolic rates of C. helgolandicus.

However, at low microplastic concentrations, this effect is not obvious. Thus, in experiments of Cole et al. (2015), females of $C$. helgolandicus, fed a mixture of phytoplankton and microplastics at a concentration of $\left(75\right.$ beads $\left.\mathrm{ml}^{-1}\right)$, for almost 9 days at a constant temperature $\left(\sim 18^{\circ} \mathrm{C}\right)$ TM levels were almost as high $\left(\sim 0.7 \mu \mathrm{L} \mathrm{O}_{2}\right.$ ind $^{-1} \mathrm{~h}^{-1} \approx 0.9 \mu \mathrm{g}$ ind $\left.^{-1} \mathrm{~h}^{-1}\right)$ as in our experiments with females consuming a natural diet without the addition of microplastics (see Table 3 ).

\section{Behavior}

The main types of behavior of copepods of the genus Calanus have long been described in the pioneering experimental works of Cannon, 1928; Lowndes, 1935; Hardy and Bainbridge, 1954 and were greatly developed later (e.g., Alcaraz et al., 1980) including some recent works (e.g., Kiørboe, 2011; Chen and Hwang, 2018).

The motor and nutritional activity of $C$. helgolandicus under natural conditions is associated with their daily diurnal vertical migrations, due to which, time spent swimming (T) varies widely from 15-20 to 90-95\% depending on day and night time events (Alcaraz et al., 1980; Svetlichny and Yarkina, 1989; Kiørboe, 2011; Chen and Hwang, 2018). During the night-time grazing period, these copepods can maintain nearly continuous mouth appendage locomotion for several minutes (up to an hour). Nevertheless, the average daily activity at a temperature of about $20^{\circ} \mathrm{C}$ is $60-70 \%$ (Kiørboe, 2011; Chen and Hwang, 2018). In large aquariums (up to $4 \mathrm{~L}$ ) time spent undergoing routine locomotion in C. helgolandicus increased from 11 a.m. to 1 p.m. and again in the evening (Svetlichny and Umanskaya, 1991).

We examined copepod behavior in the afternoon. Periodic jumps when touching the bottom with furcal bristles and short-term ascent with subsequent descending ("hop and sink"), circular swimming in the water column or intermittent movement at the bottom (resting the head against the vessel wall), represented typical behavior of $C$. helgolandicus females in the specimens we observed in relatively small vessels (approx. $100 \mathrm{ml}$ ). In all these cases, the activity of the females was carried out due to a more or less prolonged series of metachronic strokes by the mouth appendages, accompanied by small abdominal strokes. Simultaneously together with the body propulsion, the mouth appendages generated a feeding current due to which food particles were concentrated on the second maxilla in the vicinity of the mouth opening in the form of a small batch, which was then sucked into the mouth opening. This type of feeding is evident by recording the behavior of attached copepods using high-speed video recording (Svetlichny and Hubareva, 2005: our observations). In C. helgolandicus females kept under laboratory conditions with sufficient food and water conditioning, the average daily locomotor activity is about 50$70 \%$ and the frequency of blows with oral appendages in the range of $40-50 \mathrm{~Hz}$ at $20^{\circ} \mathrm{C}$ can persist for tens of days and depends only on temperature waters (Svetlichny and Yarkina, 1989). In our present experiment with $C$. helgolandicus females feed algae ad libitum, the average time spent swimming and frequency of movement of the mouth appendages $(43.9 \pm 18.1 \%$ of total observation time and $41.3 \pm 5.2 \mathrm{~Hz}$, respectively) corresponded to the usual activity level of this species at $20^{\circ} \mathrm{C}$ and remained so at the beginning of fasting or kept only in water with microplastics (Figure 8).

However, during the 7 day exposure to microplastics, the parameters of motor/feeding activities, i.e., time spent swimming and mouth appendage beat frequency, decreased 2.6 and 1.6fold, respectively. Copepods which predominantly grazed at the bottom of the vessel consumed less microplastics, and in general their behavior corresponded to starved individuals (Figure 8). Nevertheless, the mouth appendage beat frequency $(34 \pm 3.2 \mathrm{~Hz})$ of starving females was higher than for copepods which consumed microplastics $(25.7 \pm 3.5 \mathrm{~Hz})$. This confirms our conclusion, made on the basis of respiration data, that with prolonged exposure to microplastics beads, C. helgolandicus display a more rapid adaptive decrease in energy metabolism response than occurs during starvation. The adaptive nature of the decrease in the activity of copepods is confirmed by the fact that after the addition of microalgae, the time spent on swimming/feeding, increased in them according to the principle of hypercompensation (Figure 8).

In conclusion, the trends we have identified for a gradual decrease in the rate of microplastic consumption, energy metabolism, and motor activity could be caused not only by accelerated starvation, but also by the traumatic effects of 
microparticles on the copepods intestinal parenchyma, which is more pronounced when larger particles of microplastic are consumed. The likelihood of such an effect of microplastics should be verified in future experiments.

\section{DATA AVAILABILITY STATEMENT}

The raw data supporting the conclusions of this article will be made available by the authors, without undue reservation, to any qualified researcher.

\section{AUTHOR CONTRIBUTIONS}

MI, AEK, and LS conceived and planned the experiments. MI, LS, TM, KE, ET, OD, and EY carried out the experiments. KE maintained the algal culture. MI, LS, KE, and AEK contributed to the interpretation of the results. LS took the lead in writing the

\section{REFERENCES}

Alcaraz, M. T., Paffenhoffer, G., and Strickler, R. (1980). 22. Catching the algae: a first account of visual observations on filter-feeding calanoids. Evol. Ecol. 3, 241-248.

Ayukai, T. (1987). Discriminate feeding of the calanoid copepod Acartia clausi in mixtures of phytoplankton and inertparticles. Mar. Biol. 94, 579-587.

Ayukai, T., and Nishizawa, S. (1986). Defecation rate as a possible measure of ingestion rate of Calanus pacificus (Copepoda: Calanoida). Bull. Plankton Soc. Jap. 33, 3-10.

Båmstedt, U., Nejstgaard, J. C., Solberg, P. T., and Høisoeter, T. (1999). Utilisation of small-sized food algae by Calanus finmarchicus (Copepoda, Calanoida) and the significance of feeding history. Sarsia 84, 19-38. doi: 10.1080/00364827. 1999.10420449

Botterell, Z. L. R., Beaumont, N., Dorrington, T., Steinke, M., Thompson, R. C., and Lindeque, P. K. (2019). Bioavailability and effects of microplastics on marine zooplankton: a review. Environ. Pollut. 245, 98-110. doi: 10.1016/j.envpol.2018. 10.065

Boyd, C. M. (1976). Selection of particle sizes by filter-feeding copepods: a plea for reason. Limnol. Oceanogr. 21, 175-180. doi: 10.4319/lo.1976.21.1.0175

Buskey, E. J. (1998). Energetic costs of swarming behavior for the copepod Dioithona oculata. Mar. Biol. 130, 425-431. doi: 10.1007/s0022700 50263

Cannon, H. G. (1928). On the feeding mechanism of the copepods Calanus finmarchicus and Diaptomus gracialis. Brit. J. Exp. Biol. 6, 131-144.

Carotenuto, Y., Esposito, F., Pisano, F., Lauritano, C., Perna, M., Miralto, A., et al. (2012). Multi-generation cultivation of the copepod Calanus helgolandicus in a re-circulating system. J. Exp. Mar. Biol. Ecol. 418, 46-58. doi: 10.1016/j.jembe. 2012.03.014

Chen, M. R., and Hwang, J. S. (2018). The swimming behavior of the calanoid copepod Calanus sinicus under different food concentrations. Zool. Stud. 57, 1-9. doi: 10.1016/j.jembe.2017.04.004

Cole, M., Lindeque, P., Fileman, E., Halsband, C., and Galloway, T. (2015). The impact of polystyrene microplastics on feeding, function and fecundity in the marine copepod Calanus helgolandicus. Environ. Sci. Technol. 49, 1130-1137. doi: 10.1021/es504525u

Cole, M., Lindeque, P., Fileman, E., Halsband, C., Goodhead, R., Moger, J., et al. (2013). Microplastic ingestion by zooplankton. Environ. Sci. Technol. 47, 6646-6655. doi: 10.1021/es400663f

Cole, M., Lindeque, P. K., Fileman, E., Clark, J., Lewis, C., Halsband, C., et al. (2016). Microplastics alter the properties and sinking rates of zooplankton faecal pellets. Environ. Sci. Technol. 50, 3239-3246. doi: 10.1021/acs.est. 5b05905

Conover, R. J. (1962). Metabolism and growth in Calanus hyperboreus in relation to its life cycle. Rapp. Proc. Verb. Cons. Int. Explor. Mer. 153, 190-197. manuscript followed by extensive revision by AEK to achieve the final version. All authors provided critical feedback and helped shape the research, analysis and manuscript.

\section{FUNDING}

This work was supported by the Research Fund of Istanbul University (Grant Nos. 25919, 35212, and 31404), the Scientific and Technological Research Council of Turkey (Grant No. 115Y627), and the projects of the National Academy of Sciences of Ukraine (Grant No. 0114U002041).

\section{ACKNOWLEDGMENTS}

We thank the three reviewers for their comments for improving the manuscript substantially.

Coppock, R. L., Galloway, T. S., Cole, M., Fileman, E. S., Queirós, A. M., and Lindeque, P. K. (2019). Microplastics alter feeding selectivity and faecal density in the copepod, Calanus helgolandicus. Sci. Total Environ. 687, 780-789. doi: 10.1016/j.scitotenv.2019.06.009

Corner, E. D. S., Head, R. N., and Kilvington, C. C. (1972). On the nutrition and metabolism of zooplankton. VIII. The grazing of Biddulphia cells by Calanus helgolandicus. J. Mar. Biol. Assoc. U.K. 52, 847-861. doi: 10.1017/ s0025315400040595

Cowles, T. J., Olson, R. J., and Chisholm, S. W. (1988). Food selection by copepods: discrimination on the basis of food quality. Mar. Biol. 100, 41-49. doi: 10.1007/ bf00392953

DeMott, W. R. (1986). The role of taste in food selection by freshwater zooplankton. Oecologia 69, 334-340. doi: 10.1007/bf00377053

DeMott, W. R. (1988). Discrimination between algae and artificial particles by freshwater and marine copepods. Limnol. Oceanogr. 33, 397-408. doi: 10.4319/ lo.1988.33.3.0397

Desforges, J. P. W., Galbraith, M., and Ross, P. S. (2015). Ingestion of Microplastics by Zooplankton in the Northeast Pacific Ocean. Arch. Environ. Contam. Toxicol. 69, 320-330. doi: 10.1007/s00244-015-0172-5

do Sul, J. A. I., and Costa, M. F. (2014). The present and future of microplastic pollution in the marine environment. Environ. Pollut. 185, 352-364. doi: 10. 1016/j.envpol.2013.10.036

Erftmeijer, P. L. A., Riegl, B., Hoeksema, B. W., and Todd, P. A. (2012). Environmental impacts of dredging and other sediment disturbances on corals: a review. Mar. Pollut. Bull. 64, 1737-1765. doi: 10.1016/j.marpolbul.2012.05. 008

Figueroa, D. F., Cartes, J., and Figueroa, N. J. (2019). Insights to the genetic structure of Calanus helgolandicus (Calanoida: Copepoda) from deep-sea specimens in the Balearic Sea. Crustacean Res. 48, 119-132. doi: 10.18353/ crustacea.48.0_119

Fleminger, A., and Hulsemann, K. (1987). Geographical variation in Calanus helgolandicus s.l. (Copepoda, Calanoida) and evidence of recent speciation of the Black Sea population. Biol. Oceanogr. 5, 43-81.

Frydkjær, C. K., Iversen, N., and Roslev, P. (2017). Ingestion and egestion of microplastics by the cladoceran Daphnia magna: effects of regular and irregular shaped plastic and sorbed phenanthrene. Bull. Environ. Contam. Toxicol. 99, 655-661. doi: 10.1007/s00128-017-2186-3

Gamble, J. C. (1978). Copepod grazing during a declining spring phytoplankton bloom in the Northern North Sea. Mar. Biol. 49, 303-315. doi: 10.1007/ bf00455025

Gauld, D. T. (1957). A peritrophic membrane in calanoid copepods. Nature 179, 325-326. doi: 10.1038/179325a0

Gonçalves, R. J., and Kiørboe, T. (2015). Perceiving the algae: how feeding-current feeding copepods detect their nonmotile prey. Limnol. Oceanogr. 60, 1286-1297. doi: $10.1002 / \operatorname{lno} .10102$ 
Gorokhova, E., Könnecke, O., Ogonowski, M., Gerdes, Z., and Wiklund, A. E. (2018). Alterations in swimming behavior of Daphnia exposed to polymer and mineral particles: towards understanding effects of microplastics on planktonic filtrators. bioRxiv [Preprint]. doi: 10.1101/406587

Hanke, G., Galgani, F., Werner, S., Oosterbaan, L., Nilsson, P., and Fleet, D. (2013). Guidance on Monitoring of Marine Litter in European Seas. MSFD GES Technical Subgroup on Marine Litter. Luxembourg: Publications Office of the European Union.

Hansen, B., Bjornsen, P. K., and Hansen, P. J. (1994). The size ratio between planktonic predators and their prey. Limnol. Oceanogr. 39, 395-403. doi: 10. 4319/lo.1994.39.2.0395

Hansen, B., Hansen, P. J., and Nielsen, T. G. (1991). Effects of large non-grazable particles on clearance and swimming behaviour of zooplankton. J. Exp. Mar. Biol. Ecol. 152, 257-269. doi: 10.1016/0022-0981(91)90218-L

Hardy, A. C., and Bainbridge, R. (1954). Experimental observations on the vertical migrations of plankton animals. J. Mar. Biol. Assoc. U.K. 33, 409-448. doi: $10.1017 /$ S0025315400008456

Hartmann, N. B., Hüffer, T., and Thompson, R. C. (2019). Are we speaking the same language? Recommendations for a definition and categorization framework for plastic debris. Environ. Sci. Technol. 53, 1039-1047. doi: 10.1021/ acs.est.8b05297

Helenius, L., Budge, S., Duerksen, S., Devred, E., and Johnson, C. L. (2019). Lipids at the plant-animal interface: a stable isotope labelling method to evaluate the assimilation of essential fatty acids in the marine copepod Calanus finmarchicus. J. Plankton Res. 41, 909-924. doi: 10.1093/plankt/fbz062

Hidayaturrahman H., and Lee T. (2019). A study on characteristics of microplastic in wastewater of South Korea: identification, quantification, and fate of microplastics during treatment process. Mar. Pollut. Bull. 146, 696-702. doi: 10.1016/j.marpolbul.2019.06.071

Hochachka P. W., and Somero G. N. (2002). Biochemical Adaptation: Mechanism And Process In Physiological Evolution. New York, NY: Oxford Univ.

Hulsemann, K. (1991). Calanus euxinus, new name, a replacement name for Calanus ponticus Karavaev, 1894 (Copepoda: Calanoida). Proc. Biol. Soc. Washington 104, 620-621

Huntley, M., Barthel, K. G., and Star, J. L. (1983). Particle rejection by Calanus pacificus: discrimination between similarly sized particles. Mar. Biol. 74, 151160. doi: $10.1007 / \mathrm{bf} 00413918$

Huskin, I., Anadon, R., Alvarez-Marques, F., and Harris, R. P. (2000). Ingestion, faecal pellet and egg production rates of Calanus helgolandicus feeding coccolithophorid versus non-coccolithophorid diets. J. Exp. Mar. Biol. Ecol. 248, 239-254. doi: 10.1016/S0022-0981(00)00167-2

Huvet, A., Paul-Pont, I., Fabioux, C., Lambert, C., Suquet, M., Thomas, Y., et al. (2016). Quantifying the smallest microplastics is the challenge for a comprehensive view of their environmental impacts. Proc. Natl. Acad. Sci. U.S.A. 113, E4123-E4124. doi: 10.1073/pnas.1607221113

Ikeda, T. (1971). Changes in respiration rate and in composition of organic matter in Calanus cristatus (Crustacea Copepoda) under starvation. Bull. Fac. Fish. Hokkaido Univ. 21, 280-298.

Ikeda, T. (1977). The effect of laboratory conditions on the extrapolation of experimental measurements to the ecology of marine zooplankton. IV. Changes in respiration and excretion rates of boreal zooplankton species maintained under fed and starved conditions. Mar. Biol. 41,241-252. doi: 10.1007/ bf00394910

Isinibilir, M., Svetlichny, L., Hubareva, E., Ustun, F., Yilmaz, I. N., Kideys, A. E., et al. (2009). Population dynamics and morphological variability of (Calanus euxinus) in the Black and Marmara Seas. Ital. J. Zool. 76, 403-414. doi: 10.1080/ 11250000902751720

Jaschnov, W. A. (1955). Morphology, distribution and systematics of Calanus finmarchicus s.l. Zool. Zhurnal 34, 1210-1223.

Kiørboe, T. (2011). How zooplankton feed: Mechanisms, traits and tradeoffs. Biol. Rev. 86, 311-340. doi: 10.1111/j.1469-185X.2010.00148.x

Kiørboe, T., Møhlenberg, F., and Riisgård, H.U. (1985). In situ feeding rates of planktonic copepods: a comparison of four methods. J. Exp. Mar. Biol. Ecol. 88, 67-81. doi: 10.1016/0022-0981(85)90202-3

Koehl, M., and Strickler, J. R. (1981). Copepod feeding currents: food capture at low Reynolds number. Limnol. Oceanogr. 26,1062-1073. doi: 10.4319/lo.1981. 26.6.1062
Koehl, M. (1984). "Mechanisms of particle capture by copepods at low Reynolds numbers: possible modes of selective feeding," in Trophic interactions within aquatic ecosystems, eds Meyers, D. G, and Strickler, J. R (Boulder: Westview Press), 135-166.

Lee, R. F., Nevenzel, J. C., Paffenhöffer, G. A., and Benson, A. A. (1970). The metabolism of wax esters and other lipids by the marine copepod Calanus helgolandicus. J. Lipid Res. 11, 237-240.

Lee, R., Hirota, J., Nevenzel, J. C., Sauerheber, R. D., Benson, A. A., and Lewis, A. (1972). Lipids in the marine environment. Calif. Mar. Rea. Commun. 16, 5-102.

Lee, K. W., Shim, W. J., Kwon, O. Y., and Kang, J. H. (2013). Size-dependent effects of micro polystyrene particles in the marine copepod Tigriopus japonicus. Environ. Sci. Technol. 47, 11278-11283. doi: 10.1021/es401932b

Lenz, R., Enders, K., and Nielsen, T. G. (2016). Microplastic exposure studies should be environmentally realistic. Proc. Natl. Acad. Sci. U.S.A. 113, E4121E4122. doi: 10.1073/pnas.1606615113

Lowndes, A. G. (1935). The swimming and feeding of certain calanoid copepods. Proc. Zool. Soc. Lond. 3, 687-715. doi: 10.1111/j.1096-3642.1935.tb01688.x

Martens, P. (1978). Faecal pellets. Fich. Ident. Zoopl. 162:4.

Mauchline, J. (1998). "The biology of calanoid copepods," in Advances in Marine Biology, Vol. 33 (London: Academic Press), 1-710.

Mayzaud, P. (1976). Respiration and nitrogen excretion of zooplankton. IV. The influence of starvation on the metabolism and the biochemical composition of some species. Mar. Biol. 37, 47-58. doi: 10.1007/bf00386778

Meyer, B., Irigoien, X., Graeve, M., Head, R. P., and Harris, R. P. (2002). Feeding rates and selectivity among nauplii, copepodites and adult females of Calanus finmarchicus, and Calanus helgolandicus. Helgol. Mar. Res. 56, 169-176. doi: 10.1007/s10152-002-0105-3

Nival, P., and Nival, S. (1976). Particle retention efficiencies of an herbivorous copepod, Acartia clausi (adult and copepodite stages): effects on grazing. Limnol. Oceanogr. 21, 24-33. doi: 10.4319/lo.1976.21.1.0024

Ogonowski, M., Schür, C., Jarsén, A., and Gorokhova, E. (2016). The effects of natural and anthropogenic microparticles on individual fitness in Daphnia magna. PLoS One 11:e0155063. doi: 10.1371/journal.pone.0155063

Paffenhöfer, G., and Van Sant, K. B. (1985). The feeding response of a marine planktonic copepod to quantity and quality of particles. Mar. Ecol. Prog. Ser. 27, 55-65. doi: 10.3354/meps027055

Paffenhöfer, G. A., and Knowles, S. C. (1979). Ecological implications of faecal pellet size, production and consumption by copepods. J. Mar. Res. 37, 36-47.

Paffenhofer, G. A., Bundy, M. H., Lewis, K. D., and Metz, C. (1995). Rates of ingestion and their variability between individual calanoid copepodsdirect observations. J. Plank. Res. 17, 1573-1585. doi: 10.1093/plankt/17.7. 1573

Papadopoulos, L. N., Peijnenburg, K. T. C. A., and Luttikhuizen, P. C. (2005). Phylogeography of the calanoid copepods Calanus helgolandicus and C. euxinus suggests Pleistocene divergences between Atlantic, Mediterranean, and Black Sea populations. Mar. Biol. 147, 1353-1365. doi: 10.1007/s00227-0050038-x

Pavlova, E. V., and Minkina, N. I. (1987). Weight-specific respiration of marine planktonic animals with different activity. J. Gen. Biol. 48, 92-103.

Poulet, S. A., and Marsot, P. (1978). Chemosensory grazing by marine calanoid copepods (Arthropoda: Crustacea). Science 200, 1403-1405. doi: 10.1126/ science.200.4348.1403

Price H. J., Paffenhofer G. A., and Strickler J. R. (1983). Modes of cell capture in calanoid copepods. Limnol. Oceanogr. 28, 116-123. doi: 10.4319/lo.1983.28.1. 0116

Price, H. J., and Paffenhofer, G. A. (1984). Effects of feeding experience in the copepod Eucalanus pileatus: a cinematographic study. Mar. Biol. 84, 35-40. doi: $10.1007 /$ bf00394524

Reeve, M. R., and Walter, M. A. (1977). Observations on the existence of lower threshold and upper critical food concentrations for the copepod Acartia tonsa Dana. J. exp. mar. Biol. Ecol. 29, 211-221. doi: 10.1016/0022-0981(77)90066-1

Rey, C., Harris, R., Irigoien, X., Head, R., and Carlotti, F. (2001). Influence of algal diet on growth and ingestion of Calanus helgolandicus nauplii. Mar. Ecol. Prog. Ser. 216, 151-165. doi: 10.3354/meps 216151

Riser, C. W., Jansen, S., Bathmann, U., and Wassmann, P. (2003). Grazing of Calanus helgolandicus on Dinophysis norvegica during bloom conditions in 
the North Sea: evidence from investigations of faecal pellets. Mar. Ecol. Prog. Ser. 256, 301-304. doi: 10.3354/meps 256301

Rist, S., and Hartmann, N. B. (2018). Aquatic ecotoxicity of microplastics and nanoplastics: lessons learned from engineered nanomaterials. In Freshwater microplastics. Springer Handb. Environ. Chem. 58, 25-49. doi: 10.1007/9783-319-61615-5_2

Rummel, C. D., Jahnke, A., Gorokhova, E., Kühnel, D., and Schmitt-Jansen, M. (2017). Impacts of biofilm formation on the fate and potential effects of microplastic in the aquatic environment. Environ. Sci. Technol. Lett. 4, 258-267. doi: 10.1021/acs.estlett.7b00164

Scherer, C., Brennholt, N., Reifferscheid, G., and Wagner, M. (2017). Feeding type and development drive the ingestion of microplastics by freshwater invertebrates. Sci. Rep. 7, 1-9.

Secretariat of the Convention on Biological Diversity, and Scientific and Technical Advisory Panel GEF. (2012). Impacts of marine debris on biodiversity. Curr. Status Poten. solu. Montreal 67:61

Setälä, O., Fleming-Lehtinen, V., and Lehtiniemi, M. (2014). Ingestion and transfer of microplastics in the planktonic food web. Environ. Pollut. 185, 77-83. doi: 10.1016/j.envpol.2013.10.013

Sew, G., Calbet, A., Drillet, G., and Todd, P. A. (2018). Effects of concentration and size of suspended particles on the ingestion, reproduction and mortality rates of the copepod, Acartia tonsa. Mar. Environ. Res. 140, 251-264. doi: 10.1016/j. marenvres.2018.06.016

Svetlichny, L. S., and Umanskaya, A. V. (1991). Oxygen consumption cost and locomotion in Calanus helgolandicus (Crustacea, Copepoda). Okeanologia 31, 566-571.

Svetlichny, L. S., and Hubareva E. S. (2002). The effect of oxygen concentration on metabolism and locomotory activity of Moina micrura (Cladocera) cultured under hypo- and normoxia. Mar. Biol. 141, 145-151. doi: 10.1007/s00227-0020805-x

Svetlichny, L. S., and Hubareva, E. S. (2005). The energetics of Calanus euxinus: locomotion, filtration of food and specific dynamic action. J. Plankton Res. 27, 671-682. doi: 10.1093/plankt/fbi041

Svetlichny, L., Hubareva, E., Isinibilir, M., Kideys, A., Belmonte, G., and Giangrande, E. (2010). Salinity tolerance of Calanus euxinus in the Black and Marmara Seas. Mar. Ecol. Prog. Ser. 404, 127-138. doi: 10.3354/meps08475

Svetlichny, L., Hubareva, E., and Khanaychenko, A. (2012). Calanipeda aquaedulcis and Arctodiaptomus salinus are exceptionally euryhaline osmoconformers: evidence from mortality, oxygen consumption, and mass density patterns. Mar. Ecol. Prog. Ser. 470, 15-29. doi: 10.3354/meps09907

Svetlichny, L., and Hubareva, E. (2014). Salinity tolerance of alien copepods Acartia tonsa and Oithona davisae in the Black Sea. J. Exp. Mar. Biol. Ecol. 461, 201-208. doi: 10.1016/j.jembe.2014.08.012

Svetlichny L.S., and Yarkina I. (1989). Locomotion rhythms in Calanus helgolandicus (Crustacea, Copepoda). J. Zool. 68, 50-55.
Thor, P. (2002). Specific dynamic action and carbon incorporation in Calanus finmarchicus copepodites and females. J. Exp. Mar. Biol. Ecol. 272, 159-169. doi: 10.1016/S0022-0981(02)00131-4

Tsuda, A., and Nemoto, T. (1990). The effect of food concentration onthe fecal pellet size of the marine copepod Pseudocalanus newmani Frost. Bulletin of the Plankton Society of Japan 31, 83-90.

Unal, E., Frost, B. W., Armbrust, V., and Kideys, A. E. (2006). Phylogeography of Calanus helgolandicus and the Black Sea copepod Calanus euxinus, with notes on Pseudocalanus elongatus (Copepoda, Calanoida). Deep Sea Res. Pt. II Top. Stud. Oceanogr. 53, 1961-1975. doi: 10.1016/j.dsr2.2006. 03.017

Uye, S., and Kaname, K. J. (1994). Relations between fecal pellet volume and body size for major zooplankters of the Inland Sea of Japan. J. Oceanogr. 50, 43-49. doi: 10.1007/BF02233855

Vanderploeg, H. A., Paffenhöfer, G. A., and Liebig, J. R. (1990). “Concentrationvariable interactions between calanoid copepods and particles of different food quality: observations and hypotheses," in Behavioural Mechanisms of Food Selection. New York, NY: Springer NATO, 595-613.

Vroom, R. J. E., Koelmans, A. A., Besseling, E., and Halsband, C. (2017). Aging of microplastics promotes their ingestion by marine zooplankton. Environ. Pollut. 231, 987-996. doi: 10.1016/j.envpol.2017.08.088

Wilson, D. S. (1973). Food size selection among copepods. Ecology 54, 909-914. doi: $10.2307 / 1935688$

Wright, S. L., Thompson, R. C., and Galloway, T. S. (2013). The physical impacts of microplastics on marine organisms: a review. Environ. Pollut. 178, 483-492. doi: 10.1016/j.envpol.2013.02.031

Yebra, L., Bonnet, D., Harris, R. P., Lindeque, P. K., and Peijnenburg, K. T. (2011). Barriers in the pelagic: population structuring of Calanus helgolandicus and C. euxinus in European waters. Mar. Ecol. Prog. Ser. 428, 135-149. doi: 10.3354/ meps09056

Yoshikoshi, K., and Ko, Y. (1988). Structure and function of the peritrophic membranes of copepods. Nippon. Suisan. Gakk. 54, 1077-1082. doi: 10.2331/ suisan. 54.1077

Conflict of Interest: The authors declare that the research was conducted in the absence of any commercial or financial relationships that could be construed as a potential conflict of interest.

Copyright (c) 2020 Isinibilir, Svetlichny, Mykitchak, Türkeri, Eryalçın, Doğan, Can, Yüksel and Kideys. This is an open-access article distributed under the terms of the Creative Commons Attribution License (CC BY). The use, distribution or reproduction in other forums is permitted, provided the original author(s) and the copyright owner(s) are credited and that the original publication in this journal is cited, in accordance with accepted academic practice. No use, distribution or reproduction is permitted which does not comply with these terms. 